\title{
Le Dépôt général de la Guerre et la formation scientifique des ingénieurs- géographes militaires en France (1789-1830)
}

\author{
PATRICE BRET \\ 50, rue Pelleport, 75020 Paris, France
}

\begin{abstract}
Avertissement
Cette étude a fait l'objet d'une communication présentée le 2 août 1989 au XVIII Congrès International d'Histoire des sciences à Hambourg, dans le cadre du symposium Mathematics and French Revolution: Decades of Change, organisé par I. Grattan-Guinness et J. Dhombres. Que tous ceux qui m’ont encouragé trouvent ici l'expression de ma gratitude: Jean Dhombres (Ecole des Hautes Etudes en Sciences Sociales, Paris) qui m’a invité à entreprendre ce travail, Josef W. Konvitz (Newberry University, Michigan) qui a bien voulu commenter la version initiale du manuscrit, Janis Langins (University of Toronto), Eduardo L. Ortiz (Imperial College, Londres) et Marie-Anne Corvisier (Service Historique de l'Armée de Terre, Vincennes) qui m'ont fourni d'utiles informations. Je tiens à remercier tout particulièrement Anne Godlewska (Queen's College, Kingston) pour son enthousiasme lors de stimulantes discussions, et Ivor Grattan-Guinness (Middlesex Polytechnic, Enfield), pour ses critiques encourageantes et son appui réitéré.
\end{abstract}

\section{Résumé}

Le Dépôt général de la Guerre, chargé de fournir les cartes nécessaires aux armées, connut sous la Révolution une période d'instabilité. La politique ambitieuse de Calon, son directeur, se heurta à la rivalité d'autres institutions civiles et militaires. Une période de lente reconstruction s'ouvrit avec le pouvoir napoléonien qui posa les bases rationnelles de la cartographie moderne et mit fin à la précarité du statut des ingénieurs-géographes en militarisant leur corps. La création simultanée d'une Ecole d'application des ingénieurs-géographes assura dès lors une formation cohérente et de haut niveau dans le sillage de l'Ecole polytechnique, remplaçant les cours créés au Dépôt par Calon qui avaient jusqu'alors conservé jalousement leur autonomie. Puissant, qui y fut pendant vingt ans le professeur de mathématiques, introduisit l'analyse à l'école. Son œuvre fut consacrée par son élection à l'Académie des Sciences au siège de Laplace et par le succès de la nouvelle carte de France au 1/80 000. L'ensemble de la période est marqué par la prise de conscience des enjeux de la géographie, par la mise en place des outils scientifiques de la cartographie et par la professionnalisation des ingénieurs-géographes. Disposant de son école et de son journal au même titre que les grands corps techniques, le Dépôt général de la Guerre était alors, entre l'Ecole polytechnique et le Bureau des Longitudes, une institution savante reconnue par la communauté scientifique.

\section{Summary}

The Dépôt général de la Guerre, in charge of military mapping, experienced a period of change during the French Revolution. The new trends which then arose are explored here. Firstly, its director Calon failed in setting up an ambitions policy for geography, which challenged other civilian or military institutions. The courses he instituted to train surveyors (ingénieurs-géographes) collapsed. A time of slow reconstruction followed under Napoleonic rule, when the rational bases of modern cartography were laid as the ingénieurs-géographes were given a firm military status. In fact, a training school (Ecole d'application des ingénieurs-géographes) was created within the Ecole Polytechnique system, instead of the obsolete independent training courses. Henceforth, a high-level, coherent education was provided. Puissant, who was to teach mathematics there for twenty years, introduced analysis into the new school. His geodesic work was honoured by his succeeding Laplace at the Académie des Sciences, and by the success of the new 1: 80000 map of France. Eventually, the awareness of the importance of geography, the establishment of modern scientific tools in cartography, and the professionalization of the ingénieurs-géographes mark the whole period. The Dépôt général de la Guerre had its own school and journal, like any other corps of the technical Establishment. Thus it was a true scientific institution between the Ecole Polytechnique and the Bureau des Longitudes, and the scientific community recognized it as such. 


\section{Contenu}

Page 114: 1. Introduction

Page 115: 2. L'espace et le politique: problème institutionnel

Page 115: 2.1. Une profession sans statut (1791-99)

Page 119: 2.2. L'organisation de la profession (1799-1809)

Page 122: 3. Les cours du Dépôt général de la Guerre (1793-1802)

Page 122: 3.1. Le temps de l'ouverture: la direction de Calon et les cours de Callet (1793-96)

Page 123: 3.2. Le temps des rivalités: l'Ecole polytechnique (1794) et l'Ecole des Géographes (1797)

Page 125: 3.3. Le temps des velléités: les directeurs éphémères et les cours internes (1796-1801)

Page 128: 3.4. Le temps de la reconstruction: Andréossy et Pascal-Vallongue (1801-03)

Page 132: 4. L'Ecole d'application des ingénieurs-géographes, ou l'école de Puissant (1809-30)

Page 132: 4.1. Le projet de 1802-03

Page 134: 4.2. L’Ecole impériale des ingénieurs-géographes (1809-14/1815)

Page 137: 4.3. L'Ecole d'application du Corps royal des ingénieurs-géographes (1814/1815-30)

Page 138: 5. La diffusion des connaissances: Le Mémorial du Dépôt général de la Guerre

Page 141: 6. Conclusion

Page 142: 7. Annexes

Page 142: 7.1. Instructions du général Meunier, 2 janvier 1799

Page 144: 7.2. Extraits du Sommaire du travail du Dépôt général de la Guerre par Pascal-Vallongue, septembre 1801 à février 1802

Page 145: 7.3. Ordre du général Andréossy, 30 mars 1802

Page 146: 7.4. Projet de cours de mathématiques, sans date (c. 1802)

Page 148: 7.5. Règlement de l'école impériale des ingénieurs-géographes, 30 octobre 1809

Page 152: 7.6. Programme de l'école impériale des ingénieurs-géographes, 1809

Page 156: 7.7. Sommaire du Mémorial topographique et militaire, 1802-10

\section{Introduction}

Dans un petit ouvrage, le géographe Yves Lacoste a rappelé à ses confrères universitaires le caractère sensible de leur discipline:

La géographie, écrit-il, est d'abord un savoir stratégique étroitement lié à un ensemble de pratiques politiques et militaires, et ce sont ces pratiques qui exigent le rassemblement articulé de renseignements extrêmement variés, au premier abord hétéroclites...La carte est la forme de représentation géographique par excellence; c'est sur la carte que doivent être portés tous les renseignements nécessaires à l'élaboration des tactiques et des stratégies. Cette formalisation de l'espace qu'est la carte n'est ni gratuite, ni désintéressée: moyen de domination indispensable, de domination de l'espace, la carte a d'abord été établie par des officiers et pour les officiers. ${ }^{1}$

L'appellation de cartes d'état-major, qui désigne les cartes topographiques dans le langage courant, porte témoignage de ces liens historiques. Jamais sans doute ils n'ont été plus formalisés que dans la France révolutionnaire, lorsque le Dépôt général de la Guerre affirma sa double identité en 1795, en ajoutant et de la Géographie son titre

\footnotetext{
${ }^{1}$ Y. Lacoste, La géographie, ça sert d'abord faire la guerre (Paris, 1976), pp. 7-8.
} 
traditionnel. ${ }^{2}$ Dans un contexte globalement favorable sous la Révolution et l'Empire, cette union devait promouvoir une profession fondée sur ce que l'on nommait la géographie mathématique, et qui avait pour armes l'astronomie, la trigonométrie, l'analyse, voire le calcul des probabilités. ${ }^{3}$

La présente étude a pour objet d'esquisser la mise en place des moyens scientifiques propres que les ingénieurs-géographes ont alors fournis à la cartographie française, par le biais de l'enseignement et d'une diffusion spécifique. Auparavant toutefois, il est nécessaire de tracer un bref tableau de l'évolution mouvementée du statut des ingénieurs-géographes et du Dépôt de la Guerre, reflet de l'évolution des rapports entretenus avec l'espace par le politique. ${ }^{4}$

\section{L'espace et le politique: problème institutionnel}

\subsection{Une profession sans statut (1791-99)}

L'espace vécu et l'espace mythique ont été longtemps les seuls liens que le pouvoir ait entretenus avec la géographie. L'invention d'un espace mathématisé s'est faite lentement. Les ingénieurs des camps et armées du roi, ou ingénieurs-géographes militaires du Dépôt de la Guerre, qui en furent les acteurs pour le compte de l'Etat apparurent en France à la fin du XVII ${ }^{\mathrm{e}}$ siècle. ${ }^{5}$ Leur rôle, accru durant la guerre de Sept Ans, fut réduit à la paix en 1763. Le corps commença alors à s'éteindre lentement, tout

2 Le titre complet de Dépôt général de la Guerre de terre et de mer et de la Géographie se rencontre plus rarement que celui de Dépôt général de la Guerre et de la Géographie. L'éphémère existence du Musée de Géographie témoigne également de cette vocation (cf. n.11).

3 Voir Géographie mathématique, physique et politique de toutes les parties du monde, des géographes Mentelle et Malte-Brun, 15 vols (Paris, 1803) et Introduction à la géographie mathématique et critique, du mathématicien Lacroix (précède la traduction de la Géographie moderne de J. Pinkerton (Paris, 1804). Pour Sylvestre-François Lacroix (1765-1843), la géographie mathématique et critique 'a principalement pour objet la construction des cartes' (p. xxij). A la géographie mathématique (situation des lieux) et politique (limites), il ajoute le ton du pays -la géographie physique (p. clxv). Le géodésien Louis Puissant (1769-1843) emploie également le terme (Supplément au Traité de géodésie, contenant de nouvelles remarques sur plusieurs questions de géographie mathématique et sur l'application de mesures géodésiques et astronomiques à la détermination de la figure de la Terre (Paris, 1827). Outre l'application des outils mathématiques traditionnels et de l'analyse, Puissant a présenté à l'Académie deux mémoires sur l'application du calcul des probabilités à la géodésie dans les Mémoires de l'Académie des Sciences, 10 (1831) et 11 (1832).

${ }^{4}$ Nous avons conservé l'orthographe originale dans les citations. Dans les notes infrapaginales, nous avons utilisé les abréviations suivantes pour les sources manuscrites: AEP: Archives de l'Ecole polytechnique, Palaiseau; AN: Archives nationales, Paris (sous-série F17: instruction publique); DGG: Dépôt général de la Guerre. Ces archives, déposées au Service historique de l'armée de terre, sont d'accès difficile. L'embryon d'inventaire n'est utile que pour les cartons de la Correspondance topographique. Les autres côtes sont peu précises et peu fiables. Une même côte peut comporter jusqu'à dix registres, ce qui nous a contraint à préciser les dates. En outre, la côte du carton le plus utile pour le sujet (2X 3 ) ne figure pas dans l'inventaire: il s'agit d'un des cartons isolés au cinquième étage du Pavillon du roi; ENPC: Ecole nationale des Ponts et Chaussées, Paris (bibliothèque); IGN: Institut géographique national, Saint-Mandé. Quelques documents du Dépôt de la Guerre y ont été conservés à la cartothèque (carton 1762-1869); SHAT: Service Historique de l'Armée de Terre, Vincennes. Les dossiers de nombreux ingénieurs-géographes sont disponibles, soit dans le classement alphabétique 1791-1847, soit dans la sous-série X $\mathrm{X}^{\mathrm{em}}$ (état-major). La série MR (mémoires et reconnaissances) contient les papiers du conseiller d'Etat Mathieu Dumas (MR 1978). Enfin, nous avons également utilisé des abréviations pour deux ouvrages souvent cités: I.G.: Colonel Berthaut, Les ingénieurs-géographes militaires, 1624-1831: Etude historique, 2 vols, (Paris, 1898-1902); MDGG: Mémorial du Dépôt général de la Guerre, I et II, 1829-31. Nous renvoyons de préférence à cette seconde édition refondue du Mémorial topographique et militaire de 1802-10, car elle est d'accès plus facile que l'édition originale dont on trouvera les références en Annexe 7.7.

${ }^{5}$ L’ouvrage de référence sur le sujet est celui du Colonel Berthaut cité dans la note précédente (I.G.). On y joindra toujours utilement la 'Notice historique sur le Dépôt général de la Guerre', écrite en 1802 par Pascal-Vallongue, MDGG, I (1829), 115-36. 
en continuant de fournir un travail de très grande qualité, au cours duquel il s'opposait parfois aux ingénieurs de la compagnie privée qui travaillait à la réalisation de la carte de la France de Cassini. ${ }^{6}$

Avec la départementalisation et la création du Cadastre, l'Assemblée nationale constituante de 1789 et la Législative ont, les premières, utilisé sciemment la géographie pour structurer l'espace administratif et politique d'un pays et en établir une maitrise rationnelle. ${ }^{7}$ Géographes et ingénieurs-géographes devaient être les instruments naturels de ces opérations. Indubitablement, la Révolution française ouvrait de nouvelles perspectives à la géographie.

Le 17 août 1791 pourtant, la Constituante supprima le corps des ingénieurs-géographes militaires, réduit en fait de moitié depuis trente ans. II ne restait plus alors que vingt et un ingénieurs. Un seul intégra le Génie militaire, les deux tiers furent versés dans l'infanterie, les autres furent mis à la retraite ou quittèrent l'armée. En contradiction avec la politique de l'Assemblée, cette étonnante mesure témoigne surtout de la rivalité de corps qui opposait les ingénieurs-géographes aux officiers du Génie: le député qui proposa la suppression, Bureaux de Puzy, était lui-même ingénieur militaire. ${ }^{8}$

Cette mesure fut à l'origine d'une grande confusion et du vide de la production cartographique qui accompagna d'abord la Révolution, malgré un triple sursaut sous la Convention, laquelle rétablit provisoirement les ingénieurs-géographes en 1793 et créa, l'année suivante, l'Agence des cartes et le Cabinet topographique du Comité de Salut public.

Le choix du général Calon, nommé en avril 1793 à la tête du Dépôt de la Guerre pour restructurer le service, était tout à fait pertinent. Conventionnel et ancien ingénieur-géographe, il semblait bien placé pour cette tâche devenue urgente au moment où la guerre s'amplifiait à l'extérieur et gagnait l'intérieur avec le soulèvement de la Vendée. ${ }^{10}$ L'œuvre qu'il ébaucha et qui a souvent été critiquée, prend toute sa valeur dans une perspective historique, car elle constitue un premier effort pour établir la géographie en une science autonome et conquérante. A l'automne 1794, où se

${ }^{6}$ Berthaut, I.G., I, 109-10. Sur la carte de Cassini, voir la première partie de La Carte de la France, 1750-1898: Etude historique du même auteur 2 vols (Paris, 1898-99) et M. Pelletier, La carte de Cassini: l'extraordinaire aventure de la carte de France (Paris, 1990).

${ }^{7}$ Voir M. V. Ozouf-Marignier, La représentation du territoire français à la fin du XVIII siècle d'après les travaux sur la formation des départements (Paris, 1988).

${ }^{8}$ Berthaut (I.G., I, 121-5) considère Bureaux de Pusy comme le porte-parole des directeurs du Génie et cite la lettre que lui adressèrent les géographes servant dans les Pyrénées. Selon eux, les officiers du Génie étaient trop nombreux pour leurs seules attributions et souhaitaient y ajouter celles de leurs collègues, ce qu'autorisait leur formation (ibidem, 124-5). Avec quelque excès, le directeur du Dépôt de la Guerre en 1795 parla même à la Convention d'une 'mesure désastreuse combinée par un traître, sans doute pour livrer sa patrie à la merci des hordes étrangères' (Colon, Observations à la Convention nationale sur le projet d'établissement d'une école centrale des travaux publics (Paris, 7 vendémiaire an 3 [1794], p. 3).

${ }_{9}^{2}$ L'Agence des cartes de la Commission des Travaux publics représente un exemple caricatural de centralisation. Créée le 8 juin 1794, elle avait pour objectif de réunir en un seul dépôt tous les documents concernant la géographie recueillis dans la France entière. On en confia la direction à Charles-François Frérot d'Abancourt (1758-1801), ancien ingénieur-géographe responsable de la départementalisation puis de la section graphique du Cadastre. Cette entreprise monstrueuse ne put être menée à bien. Réduite à des objectifs plus réalistes, l'Agence fut absorbée deux mois et demi plus tard par le Dépôt de la Guerre, tout en conservant ses propres locaux jusqu'en décembre 1795. Abancourt dirigea alors la section topographique du Dépôt jusqu'en mars 1799.

10 Succédant aux généraux Reynier de Jarjayes (1745-1822) et Mathieu Dumas (1753-1837), Etienne-Nicolas de Calon (17261807) fut nommé le 16 avril par Bouchotte, ministre de la Guerre. Depuis le $1^{\text {er }}$ février 1793, la France était en guerre avec l'Angleterre et la Hollande, puis avec l'Espagne. Le soulèvement vendéen avait commencé le 11 mars. 
décidaient les grandes créations scientifiques de la Convention, Calon vantait 'l'organisation centrale qui se prépare pour la géographie', allusion à son grand projet de Musée de Géographie, de Topographie militaire et d'Hydrographie qui devait avorter quelques mois plus tard. ${ }^{11}$

Cet aspect novateur, inscrit dans le titre de Dépôt général de la Guerre et de la Géographie, apparaît clairement avec l'ouverture de l'institution aux diverses branches de la géographie (ancienne, moderne, physique), la mise en place de la première formation initiale spécifique aux ingénieurs-géographes, et la volonté de progrès scientifique que manifeste la création, à côté des ingénieurs, d'une division de savants dont la 'destination, écrivait Calon en février 1795, est de porter au plus haut degré de développement et de gloire les sciences de l'astronomie et de la géographie.'. ${ }^{12}$

En revanche, il est vrai que la direction de Calon, pourtant singulièrement longue en ces temps troublés quatre ans-, ne fut pas marquée par une production cartographique abondante. Cet échec relatif doit être imputé principalement à trois causes conjoncturelles externes. D’une part, après la volonté centralisatrice de l'an II qui avait regroupé sous ses ordres tous les services géographiques, les forces centrifuges l'emportèrent. Ainsi, le Bureau des Longitudes, créé en 1795, enleva au Dépôt les astronomes les plus éminents qui y avaient été officiellement rattachés (Laplace, Delambre, Méchain), et l'année suivante le service hydrographique était rendu à la Marine, à la suite du rétablissement des départements ministériels. D'autre part, les difficultés financières considérables de l'Etat sous le Directoire nuisaient au travail sur le terrain comme au fonctionnement du bureau central, par d'incessantes compressions de personnel. ${ }^{13}$ Enfin, dans le domaine même de la cartographie, le Dépôt subissait la concurrence directe du Cabinet topographique du gouvernement. Créé par Carnot en août 1794 auprès du Comité de Salut public, puis adjoint au Directoire exécutif, cet

${ }^{11}$ Lettre à Leclerc, 3 brumaire an 3, citée par Berhaut, I.G., I, 138. Le projet de Calon, publié par Numa Broc, 'Un Musée de Géographie en 1795'. Revue d'histoire des sciences, 27, (1974), 37- 43, reçut au moins un début de réalisation, comme en témoigne le titre de 'directeur du Musée Géographique' attribué à Calon dans les lettres officielles que lui adressait Abancourt entre février et septembre 1795 (SHAT, DGG, reg. 8, messidor an 2 à brumaire an 4). Ses ambitions pour la géographie furent en partie à l'origine de la disgrâce de Calon. De fait, l'originalité de sa démarche apparaît bien à travers le cas du géologue Nicolas Desmarets (17251815). En 1795, Calon l'attacha au Dépôt de la Guerre comme érudit en géographie, alors qu'il s'occupait principalement à la rédaction de la partie Géographie physique de l'Encyclopédie méthodique. En novembre 1796 au contraire, sa place était jugée étrangère à la vocation du Dépôt et supprimée par le Directoire. Quatre ans plus tard, sous la direction de Clarke, son projet d'y faire créer un Bureau central de géographie physique fut rejeté pour le même motif (SHAT, DGG, reg. 8, prairial 2 à thermidor an 5, n 341; vendémiaire an 9 à prairial an $\left.10, \mathrm{n}^{\circ} 40\right)$.

12 Lettre à Méchain, 13 pluviôse an 3, citée par Berthaut, I.G., I, 138. En annonçant à Gosselin sa nomination au Dépôt, Calon lui écrit, bien dans le style thermidorien: 'La Convention nationale déterminée à réparer l'abandon coupable dans lequel un gouvernement corrompu laisse la science la plus utile aux communications respectives des peuples, appelle avec confiance tous les savans, tous les amis de l'humanité à seconder les grands desseins qu'elle a conçus... Les sciences appartiennent à la Société entière. Les savants sont les agents naturels d'un gouvernement sage \& bienfaisant' (Paris, 27 frimaire an 3: SHAT, DGG, reg.8, vendémiaire an 3 à messidor an 4). Une liste des employés au 15 frimaire an 4 (AN. AFIII 336, dos. 1460) inscrit dans la 3e division les savants suivants: les astronomes Nouet (1740-1811) et Perny (1765-18. .), le géomètre Tranchot (1755-1815), les érudits en géographie Gosselin (1751-1830), ci-devant académicien spécialiste de géographie ancienne, Massieu (1742-1818), universitaire et conventionnel, et Desmarets, ci-devant académicien (cf. n.11), ainsi que le professeur de mathématiques Callet (cf. n.36). Delambre, Méchain et Laplace n'y figurent pas, bien que leur appartenance soit attestée ailleurs. Berthaut (I.G., I, 138) mentionne aussi l'érudit Millon pour la géographie moderne, et les traducteurs Decremps et Van den Busch. Pascal-Vallongue (MDGG, I [1829], 237) considère que les astronomes accueillis par le Dépôt avaient été 'mis, pour ainsi dire à l'abri de l'orage révolutionnaire' (cf. n.16).

${ }^{13}$ L'astronome Perny en fit l'amère expérience en Belgique (Berthaut, I.G., I, 165). 
organisme avait recruté une partie de son personnel au Dépôt de la Guerre. ${ }^{14}$ L'important travail qu'il accomplit aux armées relégua ce dernier au simple rôle de duplication de cartes et de centre d'approvisionnement en instruments scientifiques.

La restructuration qui aurait dû être induite par cette situation tarda à venir et la précarité du statut était néfaste au prestige et au bon fonctionnement de l'établissement. Le nombre d'employés fut réduit de quatrevingt-onze en septembre 1796 à vingt-neuf le mois suivant. Le secrétaire même du Dépôt dénonçait sévèrement son directeur:

La nullité des résultats du Dépôt de la Guerre eut des conséquences moins graves par l'établissement d'un cabinet topographique que les comités du Gouvernement placèrent près d'eux. Ce bureau qui a véritablement rempli le service topographique près les armées, a suivi et recueilli avec autant d'ordre que de zèle tout ce qu'il importe de conserver sur cette partie intéressante de l'art militaire... Mais il faut dire, si le Dépôt de la Guerre eût rempli sa destination, le cabinet topographique serait un double emploi, ou une émanation de l'établissement principal. ${ }^{15}$

Le climat était donc très défavorable au Dépôt lorsque la réorganisation intervint enfin le 11 mai 1797. Accusé d'avoir 'dénaturé l'objet de son institution', Calon avait été remplacé quelques jours plus tôt par le général Dupont, directeur du Cabinet historique et topographique que le Directoire réunit au Dépôt de la Guerre. ${ }^{16}$ En revanche, il en retira la Carte de la France, la géographie civile, l'astronomie et les longitudes (qui passaient au bureau du Cadastre du ministère de l'Intérieur), les archives administratives (au secrétariat du ministère de la Guerre), les archives concernant la Marine, l'Artillerie et le Génie (aux dépôts respectifs de ces armes). Le Dépôt de la Guerre se trouvait ainsi réduit à quinze employés, et les ingénieurs employés aux armées devaient être à nouveau supprimés le mois suivant, en application du décret de $1791 .{ }^{17}$ L'institution scientifique ambitieuse que Calon avait tenté de mettre en place n'était guère plus qu'un dépôt de cartes.

Les ingénieurs-géographes furent pourtant maintenus à titre provisoire, car les opérations militaires les rendaient plus nécessaires que jamais, et le Dépôt se développa donc sous les directeurs suivants, les généraux Ernouf (septembre 1797-octobre 1798) et Meunier (octobre 1798-décembre 1799). Pendant la gestion de ce dernier, une nouvelle organisation porta en juin 1799 les employés à vingt et un. Elle rétablissait aussi les artistes topographes aux armées. ${ }^{18}$

14 Ibidem, I, 137, 145,147-8. Le chef de l'administration du Cabinet topographique lui-même, le géodésien Pouillard Sainte Flore (1724-18..), ancien ingénieur-géographe passé aux Ponts et chaussées, venait du Dépôt de la Guerre.

15 Ibidem, I, 144-5, 148.

${ }^{16}$ Calon avait réussi à procurer un traitement militaire aux astronomes, ce qui lui valut, quelques jours avant son renvoi, une lettre reconnaissante de membres de l'Institut national, Laplace, Messier, Bory, Lalande, Jeaurat et Lagrange (SHAT, dos. Calon, 8 germinal an 5). Son successeur, Pierre Dupont (1765-1840), qui se rendit célèbre en 1808 en signant la capitulation de Baylen, fut le premier ministre de la Guerre de Louis XVIII en 1814.

${ }^{17}$ L'arrêté (reproduit pour l'essentiel par Berthaut, I.G., I, 150-2) prenait effet le $1^{\text {er }}$ prairial suivant, mais le $1^{\text {er }}$ messidor seulement pour la suppression des ingénieurs-géographes. Desmarets et Gosselin, de l'Institut, furent désignés, avec Barbié du Bocage et Prony, pour trier ce qui revenait au Cadastre -les cartes de Cassini et de Ferraris, et toutes les archives concernant la géographie civile, l'astronomie et les longitudes (Ibidem, 153).

18 Berthaut, I.G., I, 154-6. Contrairement à ses prédécesseurs, Jean-Augustin Emouf (1753-1827) n’avait aucune expérience en matière de géographie. La nomination de ce pur produit de la Révolution est d'abord une conséquence du coup d'État anti-royaliste du 18 fructidor. Quant au franc-maçon Hugues-Alexandre-Joseph Meunier (1751-1831), il était membre du Comité militaire. 


\subsection{L'organisation de la profession (1799-1809)}

Malgré tout, le nouveau statut restait précaire et peu satisfaisant. Une réforme plus fondamentale fut réclamée en vain par les successeurs de Meunier. Le général Clarke, ancien du Cabinet topographique du Gouvernement, fut nommé par Bonaparte à la tête du Dépôt (décembre 1799) au lendemain du coup d'Etat du 18 brumaire auquel il avait participé. A la veille de sa nomination comme ambassadeur à Florence, un an et demi plus tard, il remit tardivement au ministre un projet qui fut ajourné et renvoyé à son successeur. ${ }^{19}$

Le général d'artillerie Andréossy avait remplacé Clarke en août 1801. Le chef de la section topographique Lomet, qui quittait alors le Dépôt pour prendre la tête d'une division au ministère, lui conseilla de prendre comme sous-directeur en remplacement d'Hastrel l'officier du Génie Pascal-Vallongue, et ce choix s'avéra excellent pour le renouveau du service. ${ }^{20}$ Dès son arrivée à la direction, Andréossy impulsa un élan nouveau au Dépôt et présenta un projet d'organisation proche du précédent, qui n'eut pas plus d'écho. En fait, ses idées personnelles étaient plus révolutionnaires encore. Un second projet qu'il échafauda parallèlement, mais qui resta sans doute dans ses cartons, organisait toutes les armes savantes en un corps unique, le corps chargé des fonctions industrielles (Génie, Artillerie, géographes), subdivisé en un corps théoricien issu d'une école commune (ingénieurs militaires, officiers d'artillerie, géodésiens) et un corps auxiliaire de simples praticiens (sapeurs, mineurs, artilleurs, topographes). ${ }^{21}$

Plus raisonnablement, Andréossy engagea une politique de rationalisation de la production cartographique d'autant plus nécessaire que la formation du personnel était hétéroclite. II en fixa les objectifs dès octobre 1801, lors de la conférence régulière qu’il avait instituée, et précisait en particulier qu'il convenait:

$3^{\circ}$ de déterminer succinctement les principes d'astronomie et de géodésie ... géologie ... et la meilleure manière d'exprimer les aspects...; les bases générales de la statistique... .

$4^{\circ}$ de fixer pour le Dépôt des règles à la pratique des arts graphiques..., d'arrêter les échelles à adopter... .22

Trois mois plus tard le modèle des cabiers topographiques était défini et une table des échelles métriques, pour laquelle Andréossy avait sollicité l'avis de Lomet, était établie et bientôt diffusée auprès de tous les services publics. ${ }^{23}$

${ }^{19}$ SHAT, DGG, 2X a 3: Lettre de Clarke au ministre de la Guerre, 2 messidor an 9, et Projet de règlement pour l'organisation des ingénieurs géographes attachés au Dépôt général de la Guerre (an 9). Ce projet était annexé à un double projet d'arrêté envisageant soit le rétablissement d'un statut militaire, soit le maintien d'artistes -un troisième projet d'arrêté prévoyait d'attacher les ingénieursgéographes au Dépôt des fortifications (Génie). Henry-Jaques-Guillaume Clarke (1765-1818), comme Dupont, avait été nommé par Carnot au Cabinet topographique en 1795, et devait devenir ministre de la Guerre, de 1807 à 1814.

20 Antoine-François Andréossy (1761-1828) avait été collègue de Bonaparte à l'Institut d'Egypte, et entra plus tard à l'Académie des Sciences. L'ouvrage-recueil de documents de J. Chambon, Un général gardois sous la Révolution et l'Empire, Joseph Pascal de Vallongue (Avignon, 1974), ignore tout du passage de Pascal-Vallongue (1763-1803) au Dépôt de la Guerre. Hastrel (1766-1846) provenait du Cabinet topographique.

21 SHAT, DGG, 2X 3: projet du $1^{\text {er }}$ vendémiaire an $10-23$ septembre 1801. Selon ce projet, l'armée française ne comprenait plus que trois armes: l'infanterie, la cavalerie et le corps chargé des fonctions industrielles.

22 SHAT, DGG, 2X 3: conférence du 19 vendémiaire an 10 -11 octobre 1801.

${ }^{23}$ L'Instruction matérielle du général Meunier du 13 nivôse an 7 (voir Annexe 7.1.) mettait déjà l'accent sur la nécessité d'uniformisation, dont un autre exemple est la diffusion des modèles de reconnaissances utilisés par Tranchot, chef du Bureau topographique du Dépôt pour la Rive Gauche du Rhin (SHAT, MR 1978, papiers Mathieu Dumas). La lettre d'Andréossy à Lomet ( $\mathrm{n}^{\circ}$ 490) et la correspondance concernant la table des échelles et les projets d'uniformisation ( ${ }^{\circ} 513$, 556 à 561, 588, etc.) ont été enregistrées au Bureau central du Dépôt (SHAT, DGG, reg. 8, vendémiaire an 9 à prairial an 10). C'est S. F. Lacroix qui accuse réception de l'envoi à l'Institut (reg. 9, frimaire an 8 à fin an 10, n 3207). 
Anciens élèves de la célèbre école de Sorèze, Andréossy et Pascal-Vallongue avaient tous deux servi en Egypte. Pour sa part, Sanson, qui devait diriger le Dépôt de mai 1802 à 1812, enseignait l'architecture et la fortification dans cette même école lorsque la Révolution l'amena à entrer dans le Génie, arme dans laquelle il fut promu général en Egypte. ${ }^{24}$

Lorsque Sanson prit la direction du Dépôt, celui-ci était à nouveau tout à fait florissant, fort de quatrevingt-dix ingénieurs-géographes et d'une collection de géographie exceptionnelle: une bibliothèque de 8000 volumes, des archives de 4000 volumes et cartons, 4000 mémoires descriptifs, 4700 cartes gravées et 7400 cartes manuscrites. ${ }^{25}$ Des opérations considérables étaient en cours. En Bavière, Bonne et Henry venaient de mesurer avec des ingénieurs français et bavarois l'une des bases les plus longues -21,649 kilomètres. ${ }^{26}$ On travaillait de même à dresser les cartes de la République cisalpine, de la Ligurie, de l'île d'Elbe, de l'Helvétie, de la Souabe et des départements rhénans annexés. Dans un climat désormais propice et avec l'aide précieuse de Pascal-Vallonge qu'il conserva comme adjoint, Sanson poursuivit fermement la politique engagée par son prédécesseur et s'attacha à donner plus de cohérence à ces travaux dont les canevas devaient être coordonnés.

II poussa même cette politique plus loin, en réunissant au Dépôt de la Guerre une grande commission topographique mixte qui, de septembre à novembre 1802, fixa les normes et les signes conventionnels. Si les membres du Dépôt étaient les plus nombreux au sein de cette commission, celle-ci comprenait également Lomet, représentant le ministère, et des directeurs, inspecteurs généraux ou ingénieurs des divers corps et institutions intéressés: Ponts et Chaussées (Prony, Lesage), Marine et colonies (Decaux, Leroy), Génie (Allent), Mines (Hassenfratz, Collet-Descotils), Relations extérieures (Chrestien), Forêts (Chanlaire). ${ }^{27}$

Cette œuvre rationnelle d'envergure fut bientôt complétée par une autre commission chargée de déterminer la projection que devait utiliser la cartographie française. Réunis en janvier 1803, le mathématicien S. F. Lacroix, de l'Institut national, Sanson et trois de ses subordonnés portèrent leur choix sur la projection de Flamsteed modifiée, dont l'usage était déjà répandu en France dans les cartes à petite échelle. ${ }^{28}$ Dès lors, les bases du travail des ingénieurs-géographes français du XIX ${ }^{\mathrm{e}}$ siècle étaient posées.

${ }^{24}$ Nicolas-Antoine Sanson (1756-1824), prix de perspective de l'Ecole gratuite de dessin de Bachelier en 1771, avait enseigné à Sorèze de 1778 à 1793. Voir A. Birembaut, 'Les écoles gratuites de dessin', Enseignement et diffusion des sciences en France au XVIII siècle, s.d. R. Taton (Paris, 1964), pp. 458, 460. Sur Sorèze, J. Fabre de Massaguel, L'Ecole de Sorèze de 1758 au 19 fructidor an IV (5 septembre 1796) (Cahiers de l'Association Marc Bloch de Toulouse, 1958).

${ }^{25}$ MDGG, I (1829),135.

${ }^{26}$ Ibidem, 292. R. Norwood avait mesuré le premier arc de méridien entre Londres et York, environ 250 kilomètres (1635). J. Dixon avait mesuré plus de 110 kilomètres (un degré de latitude) pour délimiter la frontière entre la Pennsylvanie et le Maryland (1763-68).

${ }^{27}$ Le Dépôt était représenté par Sanson, Pascal-Vallongue, Clerc, Hervet, Bacler d'Albe, Epailly, Jacotin, Bartholomé, Barbié du Bocage et Hennequin. Lomet lui-même avait été chef de la section de topographie du Dépôt de 1799 à 1801 . Les travaux de la commission furent publiés aussitôt dans le Mémorial topographique et militaire, $\mathrm{n}^{\circ}$ 5, septembre 1803 (MDGG, II [1831], 1-140). Voir Annexe 7.7 .

${ }^{28}$ Les autres commissaires étaient les ingénieurs-géographes Henry, Epailly et Plessis. Pour le premier numéro du Mémorial, publié en septembre 1802 (voir Annexe 7.7.), Lacroix avait déjà donné une 'Notice sur la construction des cartes géographiques' qui analysait les différents types de projections jusqu'à celle proposée en 1789 par le mathématicien vénitien Lorgna. Il y portait déjà un jugement favorable sur la projection utilisée par Flamsteed dans son Atlas céleste, et surtout sa correction, utilisée en particulier par d'Anville (MDGG, I [1829], 17-8). En 1810, Henry devait consacrer à ce sujet un long mémoire de mathématiques (II [1831], 430587) auquel Puissant ajouta des additions en 1831 (II, 588-610). 
Cette rationalisation de la production, qui prévalut toujours dans l'œuvre consulaire, aurait dû avoir pour pendant, dans l'esprit de Sanson et des géographes, celle de la profession elle-même. ${ }^{29}$ En l'absence d'un statut unique et définitif, les perspectives de carrière étaient en effet très aléatoires. En septembre 1801, par exemple, un ancien élève du Dépôt reçu ingénieur vingt mois plus tôt, Brousseaud, était déjà réformé avec plusieurs collègues, faute de moyens. II fut contraint de continuer à servir comme simple auxiliaire. ${ }^{30}$ Le cas est loin d'être unique et tous les ingénieurs n'étaient pas régulièrement commissionnés: certains avaient des grades militaires dans d'autres corps. Malgré ces conditions précaires, le bon fonctionnement de l'établissement masquait la nécessité d'une réforme aux yeux du pouvoir. II fallut à Sanson six ans de démarches insistantes avant d'obtenir une véritable organisation que Napoléon décida à Burgos (Espagne) en novembre 1808. Définitivement décrétée en janvier 1809, la réforme créait enfin un corps d’ingénieursgéographes militaires.

La militarisation représentait, dans la France napoléonienne, une reconnaissance à laquelle les ingénieurs étaient attachés depuis longtemps jusque dans les attributs des uniformes. On verra plus bas qu'elle impliquait aussi, dans la logique du système, la création d'une école d'application qui devait assurer la cohésion et la pérennité du corps, en conférant l'unité indispensable à la réalisation des grands projets que réclamaient désormais le Dépôt de la Guerre et la communauté scientifique, et que les besoins strictement militaires retardaient malencontreusement:

L'exécution d'une nouvelle carte de France, écrivait Sanson en 1808, paraît tellement urgente, qu'on ne saurait l'ajourner, que par la nécessité impérieuse de se procurer, avant tout, les cartes des contrées extérieures que les circonstances favorables, dans lesquelles nous nous trouvons, nous permettent de lever... .

C'est ici, ajoutait-il, le lieu de parler de la mesure d'un arc parallèle, opération déjà proposée par l'Institut et dont plusieurs membres célèbres de ce corps savant, entr'autres Monsieur Delaplace [=Laplace], avaient engagé et engagent encore le général directeur du Dépôt de la Guerre à se charger, parce que le Dépôt réunit tous les élémens nécessaires pour l'exécution d'un travail de cette nature, instrumens et observateurs habiles et exercés.

La France a donné la première mesure d'un arc du méridien; elle ne laissera pas à ses voisins la gloire de completter ce travail en y joignant la mesure d'un arc du parallèle. Dans l'état actuel des choses, ce parallèle pourrait, sans obstacles, traverser toute la France et s'étendre jusqu'aux frontières de l'Autriche. L'empereur qui honore la France en accueillant tous les projets propres à reculer les bornes des sciences et des arts, a ajourné momentanément cette opération qui ne serait ni longue, ni très dispendieuse et qui donnerait à la physique et à la géographie des notions précieuses sur la figure et la nature de notre globe. ${ }^{31}$

${ }^{29}$ Dans des domaines très divers, on pourrait mettre en parallèle la mise en place du Conseil de perfectionnement de Polytechnique, de la Commission de perfectionnement de la poudre et la restauration de l'Atelier de précision, cf. P. Bret, 'Les origines de l'institutionnalisation de la recherche militaire en France (1775-1825)', XV Colloque international d'Histoire militaire, Paris, 18-23 septembre 1989 (sous presse).

${ }^{30}$ Berthaut, I.G., I, 238-9. Brousseaud (1776-1840) devint pourtant colonel.

31 Notice sur les travaux exécutés par le corps des ingénieurs géographes suivie de quelques considérations sur l'utilité de ses services, sans date [1808] (SHAT, MR $1978 \mathrm{n}^{\circ}$ 21). Laplace ne put faire aboutir son projet que sous la Restauration, dans le cadre des opérations géodésiques de la nouvelle carte de France qui se firent sous ses auspices. 
Intérêt militaire, intérêt scientifique et intérêt d'une corporation se mêlaient intimement dans ces projets qui ne virent le jour que dans les décennies suivantes. Cette conjugaison d'intérêts apparait mieux encore dans la formation et dans la diffusion des outils scientifiques de la géographie. Au reste, l'analyse de la politique scolaire du Dépôt de la Guerre est un bon indicateur de son dynamisme, de sa capacité à construire pour l'avenir et du statut scientifique attaché à la profession.

\section{Les cours du Dépôt général de la Guerre (1793-1802)}

\subsection{Le temps de l'ouverture: la direction de Calon et les cours de Callet (1793-96)}

Sous l'Ancien Régime, le recrutement des ingénieurs-géographes était toujours resté tel que l'avaient connu les autres ingénieurs avant la création de leurs écoles au XVIII ${ }^{\mathrm{e}}$ siècle. Les candidats proposés par le directeur présentaient des dessins et étaient interrogés sur les mathématiques. En 1761, l'examen, par un ingénieur en présence du directeur et de plusieurs anciens ingénieurs, 'ne s'étendoit que jusques et compris la trigonométrie rectiligne et sphérique. ${ }^{32}$ En cas d'aptitude, les aspirants devenaient surnuméraires, au Dépôt pendant un mois ou deux puis auprès d'un ingénieur qui complétait leur formation pratique..$^{33}$ Le bureau des géographes installé à Versailles après la guerre de Sept Ans semble pourtant avoir fait aussi fonction d'école de perfectionnement, avec un maitre de langues et un professeur de mathématiques. Mais il n'y avait aucune formation initiale puisque le corps ne recrutait pratiquement plus, à l'exception de quelques ingénieurs venant d'autres services. ${ }^{34}$

En 1793, Calon créa au Dépôt de la Guerre un 'cours d'instruction théorique et pratique'.35 Avec pertinence, il engagea le professeur de mathématiques Jean-François Callet. Elève de Mauduit au Collège de France et de l'abbé Marie au collège Mazarin, Callet avait déjà donné une célèbre édition des Tables de Gardiner, mais il possédait surtout une rare expérience d'enseignement. De 1774 à 1779, il avait dirigé la pension Berthaud, à Paris, préparant avec succès les élèves au concours d'entrée à l'Ecole du Génie de Mézières. ${ }^{36}$ Après plusieurs années consacrées à ses travaux personnels, il avait été nommé professeur d'hydrographie à Vannes (1788) puis à Dunkerque (1791). Fréquentant les mathématiciens et astronomes les plus éminents, il en reçut conseils et notes pour sa nouvelle édition complétée des Tables portatives de logarithmes, publiée en 1795 alors qu’il travaillait au Dépôt de la Guerre. ${ }^{37}$

${ }^{32}$ Hervet, Historique des élèves du Dépôt de la Guerre, 6 messidor an 10 (SHAT, DGG, 2X a 3). Voir aussi Berthaut, I.G., I, 140. et F. de Dainville, 'Enseignement des " géographes » et des " géomètres »', Enseignement et diffusion des sciences au XVIII siècle (cf. n.24), p. 487.

33 Ibidem.

${ }^{34}$ Dainville (cf. n.32). En 1775, le bureau du Cadastre de la Corse à Versailles comprenait toutefois une école de dessin et de mathématiques sous la surveillance d'Abancourt, alors premier élève (SHAT, dos. Abancourt). Les recherches en cours de Mlle Marie-Anne Corvisier sur les ingénieurs-géographes permettront de préciser cette question.

35 Pascal-Vallongue, 'Notice historique...' (c.f. n.5), 125. Il précise que le cours était ouvert à douze élèves. Si tel était le cas, toutes les places n'étaient pas pourvues en décembre 1795 (cf. n.39). Berthaut attribue ce chiffre à un accroissement de Meunier (I.G., I, 158). Pour sa part, Calon parle d'un total de vingt-cinq ingénieurs formés au Dépôt sous sa direction (lettre à Barras, Paris. 20 fructidor an 5 -SHAT, dos. Calon).

${ }^{36}$ Ce concours permet de juger de la qualité de l'enseignement de Callet (1744-98). Lalande (Notes relatives à Jean-François Callet, BN, MS f. fr. 12273, f $\mathrm{f}^{209-210)}$ précise qu'en 1774, sept des douze élèves présentés furent reçus par l'abbé Bossut et que pendant trois ans la pension du Génie fournit à Mézières plus d’élèves que l'Ecole militaire de Paris.

${ }^{37}$ Dans la présentation de la nouvelle édition de ses Tables, Callet cite, parmi ceux qui l'ont conseillé ou aidé: Lagrange, Laplace, Lalande, Prony, Cousin, Delambre, Servières, Borda et Garnier. 
On ne connaît malheureusement rien de son enseignement dans cet établissement. II faut se contenter d'observer la qualité de quelques uns de ses élèves, dont l'un des premiers fut Bonne, fils de l'ingénieur hydrographe et futur maréchal de camp. ${ }^{38}$ Une liste des employés du Dépôt en décembre 1795, fait état de quatre élèves dont un seul, Lathuille, devait faire une brillante carrière comme ingénieur-géographe. ${ }^{39}$

Le poste de Callet fut supprimé en novembre 1796, sous le coup de la politique de compression budgétaire du Directoire et des attaques contre l'administration de Calon. ${ }^{40}$ Cette suppression s'inscrit également dans le cadre de la politique du 'lobby' scientifique qui avait obtenu au même moment la mise en place d'une École des Géographes dans le sillage de l'Ecole polytechnique. ${ }^{41}$ C'est donc avec quelque raison que Calon se considérait comme une victime de Carnot, savant et politique acquis au système scolaire rayonnant autour de Polytechnique, et officier de l'arme du Génie, rivale des ingénieurs-géographes. ${ }^{42}$

\subsection{Le temps des rivalités: l'Ecole Polytechnique (1794) et l'Ecole des Géographes (1797)}

En effet, l'enseignement de la géodésie et de la topographie n'était plus le monopole du Dépôt de la Guerre depuis les grandes créations scolaires de la Convention. L'organisation du Cadastre de la Seine en 1794 avait dû se contenter d'un niveau de recrutement assez faible, ainsi qu'en témoigne l'étude des rapports du jury du concours ouvert en l'an II pour la nomination de vingt-cinq ingénieurs-géographes destinés à ce service. Les candidats, proposés par les ingénieurs en chef des Ponts et Chaussées, devaient lever un plan et joindre un mémoire. Ils étaient jugés sur une épreuve de triangulation et une épreuve d'arpentage, le jury examinant particulièrement le choix de la base, la familiarité avec les logarithmes et le système métrique, l'utilisation de la boussole, la rédaction et les 'talents accessoires' (lavis, dessin, écriture). ${ }^{43}$

Il fut pourtant difficile de trouver un nombre suffisant d'ingénieurs et leurs carrières ultérieures indique que certains furent peu capables de progresser. A l'occasion, le Cadastre recruta aussi d'anciens ingénieursgéographes militaires. Mais la nécessité d'un recrutement de qualité conduisit Prony à envisager une formation dans le cadre de l'Ecole centrale des Travaux publics créée le 28 septembre $1794 .{ }^{44}$

Calon s'éleva vigoureusement contre cette concurrence civile qui donnerait une formation incomplète:

Sans doute les connoissances physiques mathématiques qui y seront démontrées, sont indispensables à toutes les classes d'ingénieurs: mais où se trouve

${ }^{38}$ Berthaut, I.G., I, 137. II s'agit de Charles Bonne, dit le chevalier (1771-1839).

${ }^{39}$ Ingénieurs géographes inhérents au Dépôt de la Guerre (AN, AF III 336, dos. 1460 nº 30). Envoyé en Italie en juillet 1796, Lathuille mourut dix ans plus tard en Savoie, des suites de l'expédition d'Egypte où il avait obtenu le grade de chef de bataillon. Un autre, Salles, élève depuis janvier 1795 était en Franconie en septembre 1796. Il servait en Italie en 1801 mais n'était plus alors porté officiellement sur les listes du Dépôt. Les deux derniers, Gobillard et Pascal, n’ont pas laissé de traces.

${ }^{40}$ Callet resta en bons termes avec Calon. Il lui prêta, par exemple, un pantographe pour le service du Dépôt, qu'il récupéra sous son successeur, en juin 1797 (SHAT, DGG, reg. 8, prairial an 2 à thermidor an 5).

${ }^{41}$ Sur le 'lobby' scientifique, voir N. et J. Dhombres, Naissance d'un nouveau pouvoir: sciences et savants en France, $1793-1824$ (Paris, 1989).

42 SHAT, dos. Calon.

43 AN, F14 2146. Ce concours fera ailleurs l'objet d'une étude particulière. Auparavant, Prony avait établi un projet d'enseignement révolutionnaire formant des promotions de deux cents élèves en deux à trois mois, J. W. Konvitz, Cartography in France, 1660-1848: science, engineering and statecraft (Chicago, 1987), p. 50.

44 Contrairement aux géographes, les calculateurs du Cadastre étaient -même sans compter Legendre- des mathématiciens avertis, tels Garnier, Lanz, Plessis, Barruel, Halma, Parseval, Théveneau. 
terminée l'étude des ingénieurs militaires, des ponts et chaussées, des mines ou constructions [navales], là seulement commence l'apprentissage des ingénieur géographes. Il faut alors qu'ils aillent sur le terrein appliquer les connoissances théoriques qu'ils ont reçues, et qu'ils recommencent, pour ainsi dire, un nouveau cours pratique; car, en sortant de l'école centrale (des travaux publics), ils ne seroient que de foibles écoliers sans utilité: le but seroit donc manqué.

Le directeur du Dépôt considérait que la théorie était tout aussi bien enseignée dans son établissement et que lui seul disposait d'un fond documentaire suffisant et 'd'artistes instruits et exercés, qui opèrent continuellement', garantie d'un solide apprentissage pratique. ${ }^{45}$

Il est vrai que la pratique était limitée à l'Ecole centrale des Travaux publics. L'enseignement géographique n’y représentait guère que quelques leçons de géométrie descriptive dans les divisions de stéréotomie et d'architecture. ${ }^{46}$ L'ancien ingénieur-géographe Dupain-Triel fut bien nommé adjoint pour la stéréotomie en juin 1795, mais il démissionna sept mois plus tard et les rares exercices sur le terrain, en septembre, avaient été confiés aux officiers du Génie attachés à l'école, sous la direction d'Horace Say. ${ }^{47}$ L'objectif des études topographiques à Polytechnique était de proposer des applications de la géométrie descriptive plus que de former de futurs ingénieurs-géographes.

Aussi, d'une certaine façon, le pouvoir donna-t-il raison à Calon dès octobre 1795, puisque la loi du 30 vendémiaire an IV organisant les écoles des services publics, ou écoles d'application au sortir de Polytechnique, prévoyait la création d'une Ecole des Géographes, principalement pour le Cadastre de la France. ${ }^{48}$ Elle ne vit le jour qu'un an et demi plus tard sous la direction de Prony, associée à l'Ecole nationale aérostatique qui en formait une section alternante dans un cursus de deux ou trois ans. ${ }^{49}$ Les mathématiques, professées par Joseph Lanz, ancien officier de marine espagnol et calculateur du Cadastre, devaient occuper le tiers du temps. ${ }^{50}$ En fait les

${ }^{45}$ Calon (de l'Oise), Observations la Convention nationale... (cf. n.8).

${ }^{46}$ La stéréotomie comprenait deux leçons de perspective ( $8^{\mathrm{e}}$ et $\left.9^{\mathrm{e}}\right)$ et quatre de topographie $\left(17^{\mathrm{e}}\right.$ à $\left.20^{\mathrm{e}}\right)$, la première partie du cours d'architecture comportait des levers de plans et nivellements pour l'établissement des routes, ponts et canaux, J. Langins, La République avait besoin de savants. Les débuts de l'Ecole polytechnique: l'Ecole centrale des travaux publics et les cours révolutionnaires de l'an III (Paris, 1987), pp. 144-51. Monge et Hachette poursuivirent cet enseignement en première année de l'école, devenue Polytechnique.

47 L'application de la stéréotomie 'aux cartes et plans, et au nivellement' prévoyait des exercices topographiques dans la campagne, 'en choisissant pour cela des pays où les inégalités du terrain fussent bien prononcées', A. Fourcy, Histoire de l'Ecole Polytechnique, éd. J. Dhombres (Paris, 1987), pp. 45-6, mais J. Langins a montré les difficultés auxquelles ils se heurtèrent (La République avait besoin de savants (cf. n.46),70). D’après les informations aimablement communiquées par Janis Langins, il semblerait que J. L. Dupain-Triel (1722-c. 1805) se soit préoccupé davantage de la publication de son mémoire sur l'hydrographie de la France et de la réédition du mémoire sur la navigation de Vauban. Mais Lomet aurait donné un cours de topographie.

${ }^{48}$ Loi du 30 vendémiaire an 4, titre VII (Procès-verbaux de la Convention nationale, Paris. Impr. nat., t. 71, pp. 219-21).

49 Voir P. Bret, 'Les épreuves aérostatiques de l'Ecole Polytechnique en l'an IV: de la géométrie descriptive à l'origine de l'Ecole des Géographes' Sciences et Techniques en Perspective n 16 (1988-89), sous presse. L’Ecole des Géographes n'était pas à Meudon, comme je l'ai écrit dans cet article d'après A. Fourcy (Histoire de l'Ecole polytechnique (cf. n.47), p. 135) mais à Paris auprès du Cadastre, également dirigé par Prony (ENPC, Ms 2148).

50 Règlement pour l'Ecole des Géographes (ENPC, Ms 2148). Sur José Maria de Lanz y Zaldivar (1764-1839), voir J. A. Garcia-Diego, En busca de Betancourt y Lanz (Madrid, 1985), et J. A. Garcia-Diego et E. L. Ortiz, 'On a Mechanical Problem of Lanz', History and Technology, 5 (1988), 301-13 (références aimablement fournies par E. L. Ortiz avec lequel nous devons faire une mise au point commune sur la carrière de Lanz au Cadastre et à l'Ecole des Géographes, inconnue jusqu'à ce jour). 
élèves, sortis de Polytechnique, avaient acquis en ce domaine des connaissances suffisantes, consacrées par l'examen devant Laplace. Aussi leur enseignait-il de préférence

certaines parties de l'astronomie ... utiles aux ingénieurs géographes, telles que la manière de déterminer les latitudes \& les longitudes, la figure de la terre, les réfractions, la théorie de la lune, celle des éclipses des satellites, \&c. ${ }^{51}$

L'école accessible après une seule année à Polytechnique, recruta parfois des sujets qui avaient été jugés trop peu instruits pour les autres services. Ce recrutement, relativement médiocre malgré quelques notables exceptions, et les habitudes contractées à Polytechnique expliquent le peu d'assiduité aux cours de mathématiques. En outre, 'on ne leur faisait nullement pratiquer ce qu'on leur enseignait'. ${ }^{52}$ Ces lacunes, jointes à la rivalité préexistante entre les deux formations, conduisirent le Dépôt de la Guerre à n'accepter qu'exceptionnellement l'intégration des élèves de Prony, en dépit des demandes réitérées d'application de la loi sur les écoles des services publics qui leur ouvrait théoriquement l'accès à toutes les administrations. ${ }^{53}$ Aussi, Bonaparte ferma-t-il l'école après la suppression du Cadastre en 1802. Les élèves et les ingénieurs furent mutés dans les autres services par tirage au sort. ${ }^{54}$ Sans envisager la part de responsabilité de son propre établissement dans cet échec, Sanson portait un jugement très sévère sur l'œuvre de Prony à 'l'Ecole des Géographes, où les sujets s'aggloméraient sans en sortir, et [au] Cadastre, qui après huit ans n'avait produit que quelques plans de la banlieue de Paris' ${ }^{55}$ La situation des cours du Dépôt de la Guerre pendant la période d'existence de l'Ecole des Géographes n'avait pourtant guère été brillante.

\subsection{Le temps des velleités: les directeurs éphémères et les cours internes (1796-1801)}

Après la suppression du poste de Callot, les cours du Dépôt général de la Guerre avaient cessé. Le général Ernouf recruta à nouveau des élèves, dont le nombre fut porté à douze en 1799: 'c'étoit purement une chose de bienfaisance, car on les admettoit ne sachant absolument rien, et on leur attribuoit $60^{\#}$ par mois' écrivit plus tard Hervet, responsable de leur formation. ${ }^{56}$ L'enseignement, nécessairement rudimentaire dans de telles conditions, n'était plus assuré par un professeur choisi à l'extérieur, mais par le personnel même du Dépôt. L'archiviste-bibliothécaire Massieu puis, au printemps 1800, l'ingénieur-géographe Moynet se chargèrent des mathématiques, limitées à 'des leçons élémentaires de géométrie'; les ingénieurs-géographes La Ruelle, ancien ingénieur de la compagnie de Cassini, et Béraud, ancien ingénieur du plan de

51 Rapport non daté sur l'École des Géographes, paraphé par Sanson qui l'envoie Pascal-Vallongue (SHAT, MR 1978). Ce rapport doit faire l'objet d'une prochaine publication (cf. n.55).

52 Ibidem.

53 Art. IX du titre VII de la loi (cf. n.48). Le 11 floréal an 8, Crétet écrivait en ce sens au ministre de la Guerre (AN, F14 2146). Les élèves de l'Ecole des Géographes adressèrent aussi une pétition à Andréossy le 16 nivôse an 10 (SHAT, DGG, reg. 9, frimaire an 8 à fin an 10, n²913).

54 AEP, Art. II $\int 3$ (1803). Cf. Berthaut, I.G., I, 248, 252, 256.

55 Berthaut, I.G., I, 253. L'Ecole des Géographes a peu retenu l'attention jusqu'à ce jour et nous travaillons à réparer cette lacune. Voir Berthaut, I.G., I, 148-49, F. Artz, Development of Technical Education in France, (Cambridge (USA), MIT Press), 1966, p. 165, et J. W. Konvitz, Cartography in France... (cf. n.43), pp. 50, 140. A. Fourcy lui-même fait une confusion partielle entre l'école de Prony et les cours du Dépôt de la Guerre (Histoire de l'Ecole polytechnique (cf. n.47), pp. 227-28).

56 Hervet, Historique des élèves... (cf. n. 32). Sur le nombre d'élèves, cf. n.35. 
Verniquet, furent chargés successivement de la topographie. ${ }^{57}$ Parfois, la durée de la scolarité était brève: Desdorides fils, entré comme élève en avril 1798, fut admis neuf mois plus tard par le jury d'examen présidé par d'Abancourt, adjoint pour la division topographique. ${ }^{58}$ Le plus souvent, au contraire, le séjour des élèves se prolongeait et ils étaient surtout considérés comme un personnel complémentaire pour les basses besognes cartographiques, calques et copies. 'Sans le secours des élèves, il eut été impossible de satisfaire au service' écrivait toujours Hervet. ${ }^{59}$ II n'est donc pas étonnant que le général Andréossy jugeât l'instruction très réduite lorsqu'il prit la direction du Dépôt en août 1801.

Cette insuffisance est confirmée indirectement par un projet d'organisation du corps envoyé le mois suivant par Brossier, chef du bureau topographique d'Italie. Selon ce projet, les élèves restaient attachés à une brigade topographique aux armées, mais Brossier élevait le niveau du recrutement. Le principe de l'examen était même retenu pour l'avancement dans les grades subalternes. L'examen d'admission, réservé à des élèves de l'École polytechnique âgés de dix-huit ans, portait sur l'arithmétique et la géométrie, le dessin de paysage et de la carte et une langue, sans négliger l'écriture. Un second examen, pour le grade de sous-lieutenant, portait sur les deux premiers volumes de Bézout (arithmétique, géométrie et trigonométrie, algèbre), la fortification de campagne, l'usage des instruments de détails. Un certificat de bonne conduite du chef de la brigade était également nécessaire. L'algèbre était requise à l'examen pour le grade de lieutenant, ainsi que la tactique et les reconnaissances militaires. ${ }^{60}$

Une instruction de janvier 1799, portant la signature du général Meunier, permet de connaitre, sinon la teneur des programmes et des examens, du moins les connaissances minimales exigées des élèves pour être reçus comme ingénieurs (voir Annexe 7.1.). ${ }^{61}$ Elles se résument en cinq points, brièvement énoncés dans un certain désordre en préliminaire à une instruction plus générale sur le service des ingénieurs, à savoir:

$1^{\circ}$ géométrie et trigonométrie rectiligne;

$2^{\circ}$ dessin, à la plume et au lavis, et écriture moulée;

$3^{\circ}$ rédaction correcte;

$4^{\circ}$ principes de la perspective;

$5^{\circ}$ nivellement.

Les mathématiques sont en fait limitées au premier volume de Bézout. Aussi, force est de constater, d'une part le recul du niveau requis à cette époque pour les ingénieurs-

${ }^{57}$ Ibidem. François La Ruelle (1751-1801) avait également servi comme ingénieur auprès d'un régiment de dragons et au bureau de la Guerre avant d'entrer au Dépôt en août 1791. L'ingénieur -géographe Roger figure également comme professeur de mathématique sur un projet de tableau pour l'an 9 (SHAT, DGG, 2X ${ }^{\text {a }}$ 3). Sur les autres professeurs, cf.. n.12, 65 et 68 . On notera qu'Ernouf avait également réclamé au ministre deux exemplaires des Lecons de l'Ecole normale (lettre du 17 ventôse an 6: SHAT, DGG, reg. 8, thermidor an 5 à germinal an 6).

${ }^{58}$ Il est vrai que Desdorides était le fils du général Picault-Desdorides (1737-1801), chef de la section historique du Dépôt. Bien qu'il s'agisse d'un cas exceptionnel, il est intéressant de noter qu'Ernouf avait invité Desdorides fils en mars 1798, c'est-à-dire avant son inscription comme élève, à suivre le cours de dessin de Neveu à l'Ecole polytechnique (SHAT, DGG reg. 8, n ${ }^{\circ} 844$ et 887).

${ }^{59}$ Hervet, Historique des élèves...(cf. n.32).

${ }^{60}$ Brossier, Projet d'organisation d'un corps topographique en France, Crémone, 25 fructidor an 9 (SHAT, DGG, 2X ${ }^{\mathrm{a}}$ 3). L'auteur (1756-1832), ingénieur-géographe avant la Révolution, avait appartenu au Cabinet topographique du gouvernement. Le Cours de Mathématiques à l'usage des gardes du pavillon et de la marine (1764-69) d'E. Bezout (1737-83) avait connu de multiples rééditions jusque sous la Révolution (cf. P. Lamandé, 'Les manuels de Bézout', Rivista di storia della Scienza, 4 (1987), 339-75, et 'Des différents rôles de l'écriture dans un manuel mathématique: l'exemple de Bézout', Sciences et Techniques en Perspective, 16, (1988-89), sous presse -texte aimablement communiqué par Pierre Lamandé.

${ }^{61}$ Cf. n.115. 
géographes militaires par rapport à leurs aînés, qui devaient posséder la trigonométrie sphérique quarante ans plus tôt, d'autre part l'infériorité de leur niveau par rapport à leurs collègues civils sortis de Polytechnique et de l'Ecole des Géographes de Prony.

Au reste, le recrutement ne se limitait pas aux seuls élèves du Dépôt. D’autres ingénieurs étaient reçus directement avec une formation variée; en mars 1799, par exemple, le jury admit Gordon, ancien ingénieurgéographe 'très instruit', et Pressat, 'très exercé dans la pratique de la levée sur le terrein et [qui] a parfaitement répondu sur les mathématiques' -Bonne faisant office d'examinateur. ${ }^{62}$ La nécessité de ce recrutement externe est la contrepartie de l'insuffisance du système de formation établi au Dépôt.

Le général Clarke en prit conscience un peu tard. Comme Brossier, il comprit surtout la nécessité de lier les cours du Dépôt à l'Ecole polytechnique et même, puisque la loi l'imposait, à l'Ecole des Géographes. C'est ce qui ressort du projet qu'il soumit au ministre peu de temps avant de quitter sa direction. ${ }^{63}$

La structure du programme, très classique sinon déjà archaïque, confirme l'usage du manuel de Bézout dans la formation donnée au Dépôt. Néanmoins, ce projet propose dans son titre 2 une élévation du niveau théorique, bien qu'un souci de réalisme ait limité les exigences initiales (art. 5): les équations du second degré étaient requises dès le concours d'entrée à Polytechnique, la trigonométrie sphérique et l'application de l'algèbre à la géométrie y étaient enseignées. Le niveau minimum est pourtant bien supérieur à celui qu'envisageait Brossier et, à plus forte raison, à celui qu'exigeait Meunier pour l'examen de sortie:

$1^{\circ}$ l'arithmétique;

$2^{\circ}$ la géométrie;

$3^{\circ}$ la trigonométrie rectiligne;

$4^{\circ}$ l'algèbre jusqu'aux équations du $3^{\mathrm{e}}$ degré exclusivement;

$5^{\circ}$ le dessin de la figure et du paysage;

$6^{\circ}$ une écriture soignée et bien orthographiée.

Les connaissances exigées pour l'admission comme officier ingénieur-géographe portaient en outre sur le complément de formation acquis au Dépôt, soit au total (art. 2):

$1^{\circ}$ l'arithmétique;

$2^{\circ}$ la géométrie;

$3^{\circ}$ la trigonométrie rectiligne et sphérique;

$4^{\circ}$ l'algèbre;

$5^{\circ}$ l'application de l'algèbre à la géométrie;

$6^{\circ}$ la construction et projection des cartes géographiques, l'employ des différens instrumens dont on se sert pour la levée des plans et le nivellement; le dessin de la figure, du paysage et des cartes géographiques et topographiques, soit au

62 Rapport de Meunier au ministre de la Guerre, 9 germinal an 7 (SHAT, MR 1978). Pressat (1776-1812) se destinait aux Ponts et Chaussées. Outre des cours de physique avec Brisson, et de chimie avec Fourcroy, il avait étudié 'l'arithmétique, la géométrie, les deux trigonométries, l'algèbre jusqu'aux degrés supérieurs, et la statique' ainsi que la stéréotomie et l'architecture. II avait été employé chez un architecte, s'était engagé et avait été placé par ordre ministériel comme dessinateur auprès de l'ingénieur en chef du Morbihan, levant et dressant des plans topographiques de 1795 à 1798 (SHAT, dos. Pressat).

63 SHAT, DGG, 2X 3. Le niveau d'entrée portait donc essentiellement sur le premier volume de Bézout, mais les trois premiers étaient requis pour être ingénieur. 
lavis, soit à la plume; l'indication des différens signes que l'on employe dans les cartes; les moyens les plus exacts pour figurer avec la castramétation, la fortification de campagne;

$7^{\circ}$ les nouvelles mesures, leurs noms et leur base;

$8^{\circ}$ les reconnaissances militaires.

Enfin, l'article 3 précisait pour les grades supérieurs:

Outre les connaissances ci-dessus, les officiers géographes des deux premières classes, devront connaître:

les sections coniques;

le calcul infinitésimal;

les élémens d'astronomie;

l'application aux opérations trigonométriques et géodésiques.

Présenté en juin 1801, ce projet fut ajourné. Avec celui de Brossier, il témoigne cependant d'un consensus aux échelons supérieurs de la hiérarchie sur la nécessité de mettre fin à un recrutement anarchique en instaurant une véritable formation scientifique pour les ingénieurs-géographes. Il ouvre ainsi une époque nouvelle dans l'enseignement donné au Dépôt.

\subsection{Le temps de la reconstruction: Andréossy et Pascal-V allongue (1801-03)}

Face à la situation peu brillante dont il hérita en la matière, Andréossy agit avec célérité. Le projet d'organisation du corps qu'il présenta au ministre dès septembre 1801 prévoyait la création d'une Ecole de topographes militaires. ${ }^{64}$ Après Polytechnique et une année à l'Ecole des Géographes, les élèves devaient être reçus sur concours 'par l'examinateur de mathématiques de l'Ecole polytechnique, le directeur de l'Ecole des Géographes et le directeur du Dépôt général de la Guerre'. L'examen d'entrée devait comporter un travail sur le terrain (figuré du terrain, mesures d'angles ou de bases, observations astronomiques) et un travail de cabinet (opérations graphiques relatives à la réduction et au dessin des cartes, calculs trigonométriques, toisés).

L'enseignement qui devait être dispensé, proche de ce que proposait Clarke, portait en outre sur l'art de la guerre et la fortification, les reconnaissances militaires et la rédaction des mémoires, l'uniformisation des méthodes de figuré -l'apprentissage des langues vivantes étant également recommandé. L'examen annuel de sortie devait porter uniquement sur l'enseignement reçu dans la nouvelle école. Andréossy, artilleur, était à l'écart de la rivalité entre ingénieurs-géographes et ingénieurs militaires et très attaché, comme on l'a dit, à l'unité des armes savantes; dans le jury d'examen, le directeur du Dépôt de la Guerre siégeait avec celui du Génie et un autre général.

${ }^{64}$ Le titre 2 du projet présenté le 5 vendémiaire an 10 par Andréossy fut repris à quelques mots près par Sanson et présenté à nouveau le 9 thermidor an 10 (SHAT, DGG, 2X 3). On notera aussi que, devant l'hétérogénéité du recrutement des ingénieurs en poste, Andréossy décida en avril 1802 la création d'un registre mentionnant en particulier leurs premières études (langues, lettres, arts, sciences physiques et naturelles) et études de mathématiques, d'une part; leurs études complémentaires en dessin, architecture et cartographie, d'autre part (SHAT, DGG, 2X a 3, 12 germinal an 10; un état de service répondant à ces rubriques figure dans le dossier Pressat). 
Si l'Ecole de topographes militaires ne vit pas le jour, Andréossy organisa aussitôt un véritable enseignement, supervisé par Hervet, ancien ingénieur-géographe des camps et armées du roi et chef de la section topographique du Dépôt, que Béraud seconda dans la surveillance des études, tout en continuant de professer le dessin et le lavis de carte, ${ }^{65}$ tandis que Bartholomé se chargeait de la gravure à l'eau-forte. ${ }^{66}$ Mais c'est à Bacler d'Albe que revint l'essentiel de l'enseignement sur 'le paysage, les dessins de la topographie, des montagnes et autres parties de l'art graphique' incluant la théorie des projections. ${ }^{67}$ L'enseignement mathématique restait assuré par Moynet, ancien prêtre qui avait dirigé l'instruction des cadets-gentilhommes d'un régiment d'infanterie avant la Révolution. Sur le terrain, il exerça en outre les élèves aux opérations de mesure de base, triangulation, travaux graphiques à la planchette et à la boussole. ${ }^{68}$ Enfin, selon l'usage du temps, les meilleurs élèves servaient de répétiteurs. ${ }^{69}$

Nous sommes fort heureusement assez bien renseignés sur la réalité de l'enseignement dispensé dans les premiers mois de la direction d'Andréossy, car son adjoint Pascal-Vallongue rédigeait alors mensuellement un Sommaire du travail du Dépôt général de la Guerre (voir Annexe 7.2.). ${ }^{70}$ Pour succinct qu'il soit, cet ensemble permet de suivre la progression effective du cours de Moynet, de la fin septembre 1801 à la fin février 1802:

septembre-octobre: sphère et globe terrestre;

octobre-novembre: idem; usage des tables de logarithmes et des cercles; géométrie;

novembre-décembre: géométrie jusqu'aux surfaces, différents cercles de la sphère;

décembre-janvier: surfaces, application de la sphère et des questions de géographie;

janvier-février: trigonométrie rectiligne, réduction des angles.

La faiblesse relative de ce cours témoigne à nouveau de l'insuffisance de l'instruction antérieure que les élèves avaient déjà reçue au Dépôt. Enfin, puisqu'ils cessaient dorénavant d'être seulement des dessinateurs auxiliaires, le ministre supprima leur indemnité en février 1802: 'l'instruction qu'ils reçoivent est une espèce de salaire qu'ils restituent en faisant quelques travaux utiles'. ${ }^{71}$

Un des derniers ordres qu'Andréossy donna avant de prendre l'ambassade à Londres, à la paix d'Amiens, fournit également le détail d'un concours de sortie (voir Annexe 7.3.). ${ }^{72}$ A côté d'un levé de carte selon les différentes techniques en usage, de son

65 SHAT, DGG, 2X 3 (voir Annexe 7.2.) et Berthaut, I.G., I, 181. Ingénieur-géographe de 1756 à 1791, Jean-André Hervet (1736-1810) avait été conservateur puis directeur du Musée du Conservatoire à Versailles en 1794-95 avant de servir au cadastre (novembre 1795) puis au Dépôt de la Guerre (août 1796). Jean-Frédéric Béraud (1764-18..) était entré au Dépôt comme dessinateur en septembre 1792. Il était capitaine lors de sa mise à la retraite en 1818 -ne pas confondre avec Jean-Geneviève Béraud (17751832, polytechnicien et ingénieur-géographe militaire passé par l’Ecole des Géographes).

${ }^{66}$ Berthaut, I.G., I, 233. De 1779 à 1796, Paul-Thomas Bartholomé (1763-18..) avait participé au levé et à la gravure du plan des rues de Paris de l'architecte Verniquet.

${ }^{67}$ SHAT, DGG, 2X 3: Comité du 29 vendémiaire an 10 et Annexe 7.2. Volontaire de 1793, le peintre Louis-Albert-Guislain Bacler d'Albe (1761-1824) devint officier d'artillerie avant de servir, en 1796, comme ingénieur-géographe. Devenu général, il devait diriger le Dépôt de la Guerre en 1814-15.

68 Voir Annexe 7.2. Jean-François Moynet (1754-1832) avait été chargé de l'instruction des cadets gentilhommes de PoitouInfanterie de 1777 à la veille de la Révolution. Une lettre de mission porte que 'le $\mathrm{C}^{\mathrm{n}}$ Moynet, ingénieur géographe chargé de l'enseignement pratique de la topographie de cet établissement conduira sur le terrain les élèves ingénieurs au Dépôt et les exerce [sic] à la trigonométrie pour leur enseigner la pratique usuelle de cette science et faire l'application de la théorie qu'il leur a précédemment démontrée'. (SHAT, DGG, reg. 8, 12 messidor an 9, $\mathrm{n}^{\circ} 200$ ).
${ }^{69}$ Ibidem.
${ }^{70}$ Cf. n.116
${ }^{71}$ SHAT, DGG, reg. 8, vendémiaire an 9 à prairial an 10 (lettre à Hervet, 25 pluviôse an 10).
${ }^{72}$ Cf. n.117. 
rattachement aux coordonnées de Paris et de sa réduction, il comprenait également la rédaction d'un mémoire descriptif très élaboré, importante spécialité du Dépôt de la Guerre. Mais, en période faste pour le travail du Dépôt, le recrutement s'ouvrit également à plusieurs anciens élèves de l'Ecole des Géographes, nouvelle preuve s’il en était besoin, de la supériorité de l'école de Prony, du moins sur le plan théorique. ${ }^{73}$

Il est vrai que cette mesure répondait à une situation transitoire, au moment de la fermeture du Cadastre et en attendant la mise en place d'une réforme profonde de l'enseignement au Dépôt. Un document sur l'instruction des élèves en mathématiques révèle les ambitions nouvelles (voir Annexe 7.4.). Bien qu'il ne soit pas daté, on doit pouvoir l'attribuer à l'époque consulaire, vraisemblablement à l'administration d'Andréossy, et il dut être inspiré par un mathématicien. ${ }^{74}$ D'une part, au contraire des textes précédents, son caractère est si peu militaire que le terme n'apparaît pas une seule fois, et les préoccupations scientifiques y prédominent largement. D’autre part, la justification des connaissances géométriques, longuement développée en préambule, et la prudente gradation établie entre trois niveaux de savoir selon leur degré d'utilité indispensable (trigonométrie rectiligne), nécessaire (trigonométrie sphérique) et éventuellement utile (mathématiques transcendantes) - laisse transparaître une rét- [réticence]

${ }^{73}$ Sans parler des anciens élèves ayant servi en Egypte (Coraboeuf, Jomard, Lecesne, Bertre, Laroche), c'est le cas de Lasseret, Choppin, Béraud, en mai-juin 1802, (Ibidem). Quant au fils de Cassini, il fut peut-être victime d'anciennes rivalités. Hastrel lui refusa une place d'élève en juillet 1801. Un an plus tard, son père tentait de le faire admettre comme aide, à défaut d'être reçu comme élève (Ibidem, et reg. 9, frimaire an 8 à fin an 10).

${ }^{74}$ Cf. n.119. L'attribution de cette pièce est délicate. Son contenu et son emplacement inciteraient à la situer vers 1801-02, mais le dossier qui la contient comporte des documents entre 1798 et 1803 et n'est pas à l'abri d'un certain désordre. Le préambule historique est une référence implicite au contexte de l'époque: expédition d'Egypte, réédition de l'Histoire des mathématiques de J. E. Montucla (Paris, 1799-1802, 4 vols). Si la période de la direction d'Andréossy peut être retenue -et dans ce cas, sans doute après les cours de l'hiver 1801-02- l'auteur reste plus difficile à cerner avec précision. On doit pouvoir écarter Hervet et Moynet. Peut-on voir dans ce texte la marque de Lacroix ou de Lomet? Lacroix avait remplacé Lagrange comme professeur d'analyse à Polytechnique, à laquelle Andréossy était lié en tant que membre du Conseil de perfectionnement au titre de l'Artillerie. Dès cette époque sans doute, il rédige une notice sur les projections pour le futur Mémorial du Dépôt. Au reste, même au début de la direction de Sanson, c'est toujours à Andréossy que Lacroix recommande Regnard, qui a perdu son poste à la fermeture de l'Ecole des Géographes (SHAT, DGG, reg. 9, frimaire an 8 à fin an 10). Lomet avait, comme on l'a vu à plusieurs reprises. la confiance d'Andréossy et l'amitié de Pascal-Vallongue. Il s'attachait aussi, depuis janvier 1802, à faire rentrer au Dépôt son autre protégé Puissant, professeur à l'Ecole centrale du Lot-et-Garonne (ibidem). 
icence à l'égard d'une telle formation que certains, au sein même du Dépôt, pouvaient juger superflue. ${ }^{75}$

Le cours suit toujours très exactement le plan du manuel de référence de Bézout, tout en précisant les besoins et les apports spécifiques à l'enseignement cartographique, mais le commentaire s'inscrit dans la ligne moderniste de l'éducation mathématique depuis la Révolution:

$1^{\circ}$ l'arithmétique jusqu'à l'emploi des logarithmes, en insistant sur le système décimal et le système métrique;

$2^{\circ}$ la géométrie, surtout la théorie des triangles et la mesure des surfaces;

$3^{\circ}$ la trigonométrie rectiligne, surtout la théorie des sinus, l'usage des tables, et les procédés de nivellement;

$4^{\circ}$ la trigonométrie sphérique. Elle n'est pas considérée comme indispensable, mais son utilité est reconnue pour la réduction des angles à l'horizon et pour l'utilisation des diverses projections utilisées en géographie: 'Car suivant la qualité de géographe ajoutée à celle d'ingénieur, toute la Terre est leur domaine, et ils doivent savoir représenter des fractions plus ou moins grandes de sa surface et même sa totalité'.

$5^{\circ}$ les éléments de l'algèbre jusqu'aux équations du second degré;

$6^{\circ}$ l'application de l'algèbre à la géométrie: 'C'est ici que les élèves généraliseront leurs idées. Ils reconnoitront que la synthèse qu'on aura employée dans les démonstrations géométriques n'est pas la méthode la plus simple, qu'elle marche pesamment et qu'elle particularise toujours les questions; qu'au

${ }^{75}$ L'auteur définit également, de façon implicite, le travail d’ingénieur-géographe, aussi bien par rapport à celui de géomètrearpenteur qu'à celui d'astronome. Sa définition met l'accent sur le géographe et fait oublier le militaire, à une époque où les ingénieurs-géographes cherchaient leur sauvegarde dans un statut militaire. Cela porte à croire que l'auteur n'est pas l'un d'eux. Les mathématiciens les plus directement intéressés par l'enseignement de la géographie étaient Prony et Lanz (de l'Ecole des Géographes), Laplace (comme examinateur pour l'entrée à ladite école) et Lacroix, ancien professeur d’hydrographie. Prony était certes en bons termes avec Andréossy qui siégeait avec lui au Conseil de perfectionnement, mais il paraît peu probable qu'il ait favorisé un établissement d'enseignement rival avant la fermeture du sien. Outre ses liens avec l'école de Prony, la position éminente et le caractère de Laplace, alors sénateur, rendent peu plausible une intervention en des termes si précautionneux. L'ensemble s'accorderait mieux avec Lacroix, alors très proche du Dépôt, ou avec l'esprit indépendant de Lomet qui le portait, malgré sa position, à une certaine réserve à l'égard de la chose militaire. Pour mémoire, rappelons aussi les cours de stéréotomie et d'analyse géométrique que donnaient à Polytechnique Monge et Hachette, qui publièrent ensemble une Application de l'algèbre à géométrie. Andréossy était le collègue du premier à la section mathématiques de l’Institut d’Égypte. Enfin, deux mathématiciens moins renommés entretenaient également des liens avec la géographie et la pédagogie: Garnier (1766-1840), ancien chef des calculateurs au Cadastre et suppléant de Fourier à Polytechnique pour l'analyse algébrique, et Halma (1755-1828), son subordonné au Cadastre et ancien secrétaire du Conseil de Polytechnique, qui devait enseigner les mathématiques au Prytanée de Paris et la géographie à l'école spéciale militaire de Fontainebleau. Praticiens ou théoriciens de la géodésie, Delambre, Lagrange et même Legendre malgré son influence attachaient en fait peu d'intérêt à son enseignement. Reste Puissant, qui tentait de regagner Paris avec l'appui de Lomet. Sur les mathématiciens français, voir I. Grattan-Guinness, Convolutions in French Mathematics, 1800-1840, 3 vols (Bâle, 1990). 
contraire l'analyse les généralise, qu'elle exige souvent moins d'effort d'esprit, qu'elle est plus expéditive et presque toujours plus élégante'. ${ }^{76}$

$7^{\circ}$ un traité des projections géographiques. ${ }^{77}$

Quant aux mathématiques transcendantes (calcul différentiel et intégral), nécessaires pour les opérations géodésiques jusqu'alors confiées à des astronomes, elles devaient faire ultérieurement l'objet d'une éventuelle formation complémentaire des ingénieurs-géographes.

La réalité était bien en-deçà de ces projets et la situation d'un enseignement assuré par des ingénieurs dans une école sans existence officielle restait précaire. Les besoins de la cartographie ne tardèrent pas à éloigner les professeurs du Dépôt. A la paix d'Amiens, en 1802, Bacler d'Elbe partit dresser la carte d'Italie et Moynet, celle de l'île d'Elbe. ${ }^{78}$

\section{L'Ecole d'application des ingénieurs-géographes, ou l'école de Puissant (1809-30)}

\subsection{Le projet de 1802-03}

La nouvelle menace de suppression des ingénieurs-géographes que laissait présager l'échec du Cadastre et de l'école des Géographes rapprocha par la force des choses civils et militaires. Prony comptait sur le directeur du Dépôt de la Guerre pour placer le personnel de son école, et Sanson s'efforça d'obtenir d'urgence la création d'une véritable école d'application auprès du Dépôt. Ce projet se plaçait délibérément dans la continuité de l'école de Prony dont elle conservait le recrutement, la structure et le programme. Pour justifier cette réouverture à l'occasion de la nouvelle organisation qui devait être donnée au corps, Sanson s'appuyait sur le développement récent de la cartographie à l'étranger. ${ }^{79}$

Son projet se limitait à une structure de huit élèves tirés de Polytechnique, avec deux professeurs, un pour les 'sciences mathématiques et phisiques appliquées à la construction des cartes et au levé des plans', 'l'autre pour la topographie, le paysage et la

\footnotetext{
${ }^{76}$ Cette formulation est très proche de celle de Monge dans les Developpemens sur l'enseignement adopté pour l'Ecole centrale des Travaux publics, reproduits par J. Langins, La République avait besoin de savants (cf. n.46) p. 248. On peut la rapprocher de celles de Lacroix dans son Traité élémentaire de calcul différentiel et de calcul intégral (1802) et son Essai sur l'enseignement en général et sur celui des mathématiques en particulier (1805) que cite J. Dhombres, 'Enseignement moderne ou enseignement révolutionnaire des sciences ?', Histoire de l'éducation, $\mathrm{n}^{\circ} 42$ (1989), 55-78 (pp. 66 et 68). Les manuels de Lacroix sur les différentes parties des mathématiques concurrençaient déjà ceux de Bézout: voir l'exemple étudié par P. Lamandé, 'Deux manuels mathématiques rivaux, le Bézout et le Lacroix, ancien contre nouveau régime en calcul infinitésimal', Wiss. Z. WPU. Rostock, série G, 37, (1988), 16-25.

77 On notera qu'un article de Lacroix sur les projections ouvre le premier numéro du Mémorial de septembre 1802 et fut vraisemblablement rédigé au printemps (voir Annexe 7.7.). Peut-on déduire des divers points exposés dans les notes précédentes que Lacroix aurait pu inspirer ce programme, ou qu'Andréossy aurait caressé un moment l'ambition d'utiliser ses talents de pédagogue ? Le fait mériterait d'être éclairci. Une démarche de Lomet pour le compte de Puissant n'est pas non plus à exclure. Sa Géométrie avait reçu un bon accueil d'Andréossy, et il devait publier dans le numéro de septembre 1803 une 'Analyse appliquée aux opérations géodésiques' (cf. sections 5).

${ }^{78}$ Dans l'hiver précédent déjà, Moynet avait dû faire valoir son mauvais état de santé pour rester à Paris et reprendre ses cours (SHAT, DGG, reg. 8, vendémiaire an 9 à 10, nº 370ter).

${ }^{79}$ Berthaut (I.G., I, 253) cite une lettre impatiente de Prony à Sanson sur le réemploi de ses employés. P. Vallongue mentionne la récente organisation de la topographie militaire en Espagne et les projets en Autriche (MDGG, I[1829], 136, 280).
} 
gravure. ${ }^{80}$ Par un contrat passé avec la géographe napolitain Rizzi-Zannoni, celui-ci aurait dû en devenir directeur en échange de la livraison de sa production cartographique à la France. ${ }^{81}$

Sanson avait soumis le programme à l'approbation du Conseil de perfectionnement de Polytechnique dont il était membre. II reprenait l'intégralité de celui de l'ancienne école 'en ajoutant aux différents articles qu'il contient des parties qui [lui] ont paru nécessaires'. ${ }^{82}$ Tel qu'il fut adopté, ce programme se divisait en cinq parties:

$1^{\circ}$ partie mathématique, comprenant un supplément à la trigonométrie (rectiligne et sphérique), et l'astronomie. Dans ce dernier domaine, les références explicites qu'il faisait à l'Astronomie de Lalande et au Système du monde de Laplace ne surent pas retenues officiellement, et l'on mettait l'accent sur 'les principes de la sphère, la mesure du temps, la théorie des parallaxes et des réfractions..., la théorie des sphérö̈des elliptiques..., la théorie générale des projections, [et] la théorie des perpendiculaires à la méridienne, avec application à la carte de France', qui devait devenir un cheval de bataille du Dépôt de la Guerre;

$2^{\circ}$ sciences physiques, comprenant la minéralogie et la physique;

$3^{\circ}$ art du dessin: mise au trait et au lavis en teintes plates, dessin représentatif des objets, carte militaire et profil de terrain, gravure, plan-relief;

$4^{\circ}$ pratique: opérations astronomiques et géodésiques sur le terrain. calculs astronomiques et géodésiques relatifs à ces opérations, travail graphique relatif à ces opérations;

$5^{\circ}$ 'Connoissances accessoires considérées dans leur généralité: physico-chimiques, économiques, historiques, militaires, langues': à mérite égal, les langues anciennes (grec, latin) et vivantes (allemand, anglais, italien) devaient donner la préférence pour les promotions. ${ }^{83}$

Malgré le soutien du rapporteur à la section de la guerre du Conseil d’Etat, le général Mathieu Dumas prédécesseur de Calon à la direction du Dépôt- l'Ecole spéciale de Géographie ne vit pas le jour. Les trois projets de Sanson sur le Dépôt, le corps et l'école se heurtèrent particulièrement à l'hostilité du général Gouvion Saint-Cyr, qui considérait même que les ingénieurs-géographes étaient inutiles, les reconnaissances militaires pouvant être confiées aux officiers du Génie ou aux officiers d'Etat-major. ${ }^{84}$

80 Projet d'articles supplémentaires au projet d'arrêt sur l'organisation des ingénieurs géographes (art. 4), annexé à la copie du Rapport fait aux Consuls par le ministre de la Guerre le 14 vendémiaire au 11 de la République que Sanson envoya à Mathieu Dumas (SHAT, MR 1978).

81 Berthaut, I.G., I, 220. A. Rizzi-Zanonni (1736- 1814) avait des ambitions plus grandes: il demandait à être général commandant les ingénieurs-géographes, membre de l'Institut et du Bureau des Longitudes (Ibidem, 219).

82 Sanson, Rapport fait au Conseil de perfectionnement sur l'Ecole d'application des Ingénieurs Géographes [décembre 1802] (AEP, Art. II \$3). Le siège des ingénieurs-géographes au Conseil de perfectionnement, occupé depuis l'origine par Prony, avait échu au Dépôt général de la Guerre en 1802. Prony y siégea dès lors au titre des Ponts et Chaussées.

83 Programme de l'instruction à donner aux élèves de l'Ecole des ingénieurs-géographes à établir au Dépôt général de la Guerre. L'exemplaire du Conseil de perfectionnement (AEP, Art. II \3) ne diffère de celui que Sanson avait envoyé à Mathieu Dumas le 12 frimaire an 11 (SHAT, MR 1978 n $^{\circ} 5$ et DGG, 2X 3) que pour les rectifications apportées au programme d'astronomie.

${ }^{84}$ Minuttes corrigées du rapport et des projets d'arrêtés concernant l'organisation du Dépôt gen ${ }^{a l}$ de la Guerre, celle des ingénieurs géographes \& celle de l'Ecole spéciale de géographie \& topographie (SHAT, MR 1978, Papiers Dumas) et projets imprimés rapportés au Conseil d'Etat par Dumas, n 649 du 15 nivôse an 11, et par Lacuée, n 972 du 17 prairial an 12 (SHAT, DGG, 2X ${ }^{\text {a }}$ 3). Voir aussi Berthaut, I.G., I, 253-6. 
Une nouvelle tentative en juin 1804, défendue au Conseil d’État par le général Lacuée, n’eut pas plus de succès. Pourtant, quoique le Dépôt continuât de recevoir des élèves, l'enseignement géographique était réduit à sa plus simple expression. La fermeture de l'Ecole de Prony, l'échec du projet de Sanson et la militarisation de l'Ecole polytechnique -dont le même Lacuée fut nommé gouverneur dès août 1804- eurent pour conséquence un renforcement de la formation géographique dans cette dernière. Le cursus comporta dorénavant l'exécution de six dessins de cartes, 'tant en plan géométral qu'en perspective.' Des ingénieursgéographes du Dépôt furent chargés de cette partie, comme professeurs externes auprès de Gay de Vernon: Castres de Vaux en 1804-05, et Nicolas l'année suivante. ${ }^{85}$

\subsection{Ecole impériale des ingénieurs-géographes (1908-14/1815)}

Lorsque Napoléon se décida à donner un statut militaire au corps des géographes, il étendit logiquement le privilège de Polytechnique et lui en réserva l'accès. En outre, le nombre d'ingénieurs devait augmenter, ce qui rendait plus pressants les besoins d'une école. ${ }^{86}$

Le règlement de l'Ecole impérale des ingénieurs-géographes créée au Dépôt sous l'autorité du directeur fut approuvé le 30 octobre 1809 par le ministre de la Guerre, l'ancien directeur Clarke (voir Annexe 7.5.). ${ }^{87}$ Reprenant en grande partie le projet de 1802-03, cette structure s'apparentait à la fois à l'ancienne Ecole des Géographes et aux cours du Dépôt. L'enseignement était confié à trois ingénieurs-géographes: un professeur de mathématiques appliquées, un professeur de dessin de la carte, un autre de paysage et de gravure. Une Commission d'instruction, présidée par le directeur, comprenait les trois professeurs, des ingénieurs désignés annuellement et le secrétaire général. Elle devait examiner les élèves au moins une fois par trimestre, et proposer des améliorations à apporter à l'enseignement, sous la tutelle obligée du Conseil de perfectionnement de l'Ecole polytechnique.

Le premier semestre était consacré à la théorie et à la pratique des calculs géodésiques, du dessin topographique et du paysage, outre des essais de gravure et de plans-reliefs à raison de trois leçons hebdomadaires. ${ }^{88}$ Le second semestre comprenait les levés sur le terrain, leur exploitation et mise au net, ainsi qu'un résumé de la théorie. Des exercices d'application et des observations astronomiques complétaient la formation, de même que le travail personnel sur les ouvrages officiels dorénavant disponibles: le Mémorial topographique et militaire, publié pur le Dépôt depuis 1802, le Traité de géodésie et le Traité de topographie, d'arpentage et de nivellement de Puissant,

${ }^{85}$ Le projet rapporté par Lacuée en 1804 (cf. n.84) constituait un retour en arrière quant au recrutement des douze élèves: aucun privilège de l'Ecole polytechnique n'y est spécifié. Les opérations sur le terrain furent rétablies dans cette dernière. Voir A. Fourcy, Histoire de l'Ecole polytechnique (cf. n. 47), pp. 246, 261, 268, 277 et les notices de l'édition de J. Dhombres, pp. 153 , 182. Fourcy indique aussi que le temps imparti à la topographie diminua en première année, celle que suivaient les futurs ingénieursgéographes $(6 \%$ en $1799,4 \%$ à partir de 1806) et varia en seconde année: $6 \%$ en 1806 et 1818, mais 3\% en 1812 et $4 \%$ en 1827 (Ibidem, 376-9). Henri-Alexandre-Léopold de Castres de Vaux (1771-1832), élève de la dernière promotion de Mézières, n’était entré au Dépôt qu'en juin 1803, après avoir servi dans l'émigration. Au contraire, Jean-Claude Nicolas (17..- 18..), avait déjà une longue carrière d'ingénieur-géographe avant son entrée au Dépôt en décembre 1793 (en particulier aux Affaires étrangères et au bureau de la Corse à Versailles).

\footnotetext{
${ }^{86}$ L'effectif devait passer de quatre-vingt-un à quatre-vingt-dix en janvier 1809 (Berthaut, I.G., II, 129).

${ }^{87}$ Règlement général d'instruction pour l'Ecole Impériale des Ingénieurs Géographes (cf. n.120).

88 Ibidem.
} 
parus respectivement en 1805 et $1807 .{ }^{89}$ Enfin, l'examen de sortie, devant un jury composé du directeur et de deux ingénieurs-géographes chevronnés, portait sur la scolarité (conduite, intelligence, travail) et sur les connaissances acquises à l'Ecole même -et non pas à Polytechnique, ce qui devait encourager l'assiduité.

L'Ecole impériale, héritière directe des cours fondés par Calon et héritière lointaine de celle de Prony, devait vite s'affirmer comme l'école de Puissant qui, tel Cauchy à l'Ecole des Ponts et Chaussées, resta vingt ans l'omnipotent professeur de mathématiques et dont l'influence sur l'enseignement fut déterminante. Né en 1769, d'origine modeste et tôt orphelin, Puissant avait reçu une éducation rudimentaire et pratiqué l'arpentage chez un notaire avant d'être pris en charge par Lomet, alors ingénieur des Ponts et Chaussées à Agen, qui lui donna une solide formation théorique et pratique (1786-90). Après trois ans au Dépôt de la Guerre, il fut employé comme ingénieur-géographe à l'armée des Pyrénées occidentales (1793-95). Rappelé au Dépôt en septembre alors qu'il avait été reçu quatre mois plus tôt professeur à la future Ecole centrale du Lot-etGaronne, il profita du séjour dans la capitale pour suivre les cours d'analyse transcendante de Lagrange et de Fourier à l'école polytechnique où Lomet était conservateur des modèles. Ayant finalement opté pour l'enseignement, il rejoignit son poste à Agen et commença sa longue carrière de pédagogue en février 1797. Tournant le dos aux manuels classiques, tels ceux de Bézout ou de Bossut, Puissant prit pour guides les ouvrages les plus modernes: l'Algèbre de Clairaut dans l'édition récemment mise à jour par Lacroix et Théveneau, qui comportait également l'arithmétique, la Géométrie de Lacroix et surtout celle de Legendre, la Géométrie descriptive et l'Application de l'algèbre à la géométrie de Lacroix, la Statique de Monge, l'Architecture bydraulique de Prony, ainsi que 'quelques ouvrages du citoyen Lagrange qui peuvent entrer dans les élémens'. S’il prépara avec succès les élèves au concours d'entrée à l'Ecole polytechnique, but affiché des cours, il s'attachait surtout à mettre en pratique une pédagogie d'ouverture et de rigueur:

...je cherche bien moins à fatiguer l'attention de mes élèves par des préceptes difficiles qu'à exciter le développement de leur intelligence et à former leur esprit à

${ }^{89}$ Le choix de ces ouvrages manifeste clairement l'importance de leur auteur dans ce domaine, dès avant la création de l'école. Puissant avait aussi donné un article important dans le Mémorial en 1803 (cf. section 5). Ses deux traités étaient déjà bien connus voir I. Grattan-Guinness (cf. n .75) pp. 414-8, 1205-6- et lui assurèrent une renommée mondiale (Schumacher et Gauss devaient donner une traduction de l'édition de 1819). Sa Topographie devait devenir 'le Manuel des ingénieurs des différens services publics et des géographes qui y trouvent une théorie complète des projections des cartes que l'on chercherait vainement ailleurs' ([Lomet], art. 'Puissant' in Arnault, Jay, Jouy, Norvins, Biographie nouvelle des contemporains (Paris, t. 17, 1824). On notera le retour de la pratique des manuels officiels que Polytechnique avait abandonnée en 1806-07, mais devait reprendre en 1811-12 (J. Langins, 'The Ecole polytechnique and the French Revolution: merit, militarization, and mathematics', communication au symposium Mathematics and the French Revolution: decades of change, au 18th International Congress of History of Science, Hambourg-Munich, 1989).

${ }^{90}$ L. Puissant: Lettre au ministre de l'Intérieur, Agen, 10 brumaire an 7 et Réponses faites par le professeur de mathématiques par le professeur de l'école centrale aux questions énoncées dans la lettre du ministre de l'Intérieur du 20 floréal an 7, Agen, 29 prairial an 7 (AN, F17 $\left.1343^{\mathrm{B}}\right)$. Les résultats de l'enquête sur l'enseignement des mathématiques dans les écoles centrales sont analysés par P. Lamandé, 'La mutation de l'enseignement scientifique en France (1750-1810) et le rôle des écoles centrales: l'exemple de Nantes', Sciences et Techniques en Perspective, 15 (1988-89), 15. 
l'observation. Enfin c'est pour les accoutumer de bonne heure à classer leurs idées avec ordre et à les rendre avec clarté que je les oblige à faire l'analyse du sujet qui a été traité dans chaque leçon. ${ }^{91}$

Parallèlement à ses cours, Puissant prépara sa Géométrie, fondée sur l'analyse algébrique (1801). ${ }^{92}$ A Lomet qui s'efforçait de faire valoir les travaux de son protégé auprès de lui, Andréossy répondit que, pour recevoir 'un mathématicien aussi profond', il attendait l'organisation nouvelle du corps 'dont les travaux ne sont qu'une application exacte des meilleures théories'. ${ }^{93}$ Après s'être occupé des opérations géodésiques à l'île d'Elbe et en Italie, Puissant publia en 1803 une 'Analyse appliquée aux opérations géodésiques' (voir section 5), fut promu au rang de chef d'escadron et nommé professeur de mathématiques à l'Ecole spéciale militaire de Fontainebleau (transférée à St-Cyr en 1808). Il y développa ses travaux et rédigea les traités qui installèrent fermement sa renommée comme mathématicien et pédagogue. ${ }^{94}$ Dès lors, il aspirait à la création de l'Ecole d'application dont il devint naturellement le principal professeur et chef des études le 24 mars 1809.

Le programme adopté par le Conseil de perfectionnement est proche de celui proposé six ans plus tôt, mais présenté selon une classification différente. Il comporte principalement deux grandes parties qui structurent l'année de scolarité (voir Annexe 7.6.). ${ }^{95}$

Théorie: trigonométrie, astronomie, géodésie, physique, géologie. Les connaissances militaires initialement prévues dans cette partie en ont été écartées. Dans cette nouvelle classification, la physique a pris le pas sur la géologie, qui remplace la minéralogie. Mais la modification la plus significative, qui porte à l'évidence la marque de Puissant, est l'apparition de la géodésie, distinguée de l'astronomie: ${ }^{96}$ elle comprend la 'théorie analytique du sphéroïde terrestre; application de cette théorie à la recherche des formules employées pour calculer les longitudes, les latitudes, les azimuths, les différences de niveau, \&c'.

Pratique: opérations sur le terrain, calculs, dessin (auquel on a ajouté les échelles).

Une partie annexe porte toujours sur les Connaissances accessoires considérées dans leur généralité (physicochimiques, économiques, historiques, militaires, langues). C'est presque mot pour mot le cinquième point du programme de 1802, duquel on a retiré la connaissance des langues mortes et celle de l'italien, évolution qui dénote une orientation résolument moderne de la géographie.

${ }^{91}$ Lettre au ministre de l'intérieur, Agen, 10 brumaire an 7 (AN, F $\left.{ }^{17} 1343^{B}\right)$. Pour une étude rapide des cours de Puissant à l'école centrale, voir M. Luxembourg, 'Contribution à l'étude des écoles centrales: l'école centrale d'Agen (21 novembre 179630août 1802; an V-an X), Revue de l'Agenais, 89 (1963), 229-46 et 293-322 (pp. 305-7). L'auteur conclut à l'échec de ces cours d'un niveau trop élevé. 1801.

92 Recueil de diverses propositions de géométrie, résolues et démontrées par l'analyse algébrique, d'après les principes de Monge et de Lacroix, Agen,

\footnotetext{
93 Andréossy et Lomet, 29 nivôse an 10 (SHAT, DGG, reg. 8, vendémiaire an 9 à prairial an 10, n 465). Lomet lui avait envoyé la Géométrie de Puissant (cf. n.92).

${ }^{94}$ En 1809, Puissant donna aussi, avec ses collègues de St-Cyr, un Cours de mathématiques rédigé pour l'usage des écoles militaires qui eut plusieurs éditions. Sur la réception de l'œuvre de Puissant, voir I. Grattan-Guinness (cf. n.75). Sur sa vie et son œuvre, voir Elie de Beaumont, Eloge historique de Louis Puissant, lu dans la séance publique annuelle du 14 juin 1869 (Paris 1869), p. 64 -reproduit dans les Mémoires de l'Académie des Sciences, 37 (1870), pt. 2, xi-lxiv. Lomet dans la Biographie nouvelle des contemporains (cf. n.89) et Parisot dans la Biographie Michaud (cf. n.114) ont donné des notices bien informées. Enfin, il existe plusieurs dossiers importants sur Puissant: celui d'ingénieur-géographe (SHAT, X ${ }^{\mathrm{em}}$ 176), celui de membre de la Légion d'Honneur (AN, LH** 2239/64) et celui d'académicien (archives de l'Académie des Sciences).
}

95 Cf. n.122.

${ }_{96}$ Par ce changement de terminologie, l'Ecole d'application anticipait sur Polytechnique (cf. n.99). 
Pour la première fois les élèves reçurent un enseignement de haut niveau parfaitement adapté aux besoins du service. Reléguant les cours traditionnels de Bézout ou Bossut, le Dépôt adoptait les conceptions modernistes d'une éducation mathématique privilégiant l'analyse. ${ }^{97}$ Le corps des ingénieurs-géographes, qui venait d'être doté d'un véritable statut, y gagna non seulement une plus grande compétence, mais aussi une plus grande cohérence, que l'absence de perspective de carrière et la diversité du recrutement n'avaient pu assurer jusqu'alors. Sanson y veillait particulièrement:

Plus que jamais, écrivait-il à un de ses subordonnés en avril 1812, le corps doit se persuader qu'il ne faut point que les uns s'occupent de géodésie à l'exclusion des autres, ainsi que cela s'est pratiqué jusqu'à ce moment; et que tous doivent être indistinctement occupés aux divers genres de travaux que l'administration fait exécuter, puisque leur instruction le permet et que le gouvernement l'exige. ${ }^{98}$

La qualité de la formation des ingénieurs-géographes était telle que leur école survécut sans mal aux changements de régimes de $1814 / 15 .^{99}$

\subsection{L'Ecole d'application du Corps royal des ingénieurs-géographes (1814/1815-30)}

En août 1815, le comte d'Ecquevilly, nouveau directeur du Dépôt général de la Guerre, rendit même hommage à l'œuvre de Sanson et de Puissant:

L'Ecole d'application a compté son perfectionnement presque dès sa naissance: elle est établie sur d'excellentes bases; elle a déjà fourni dans le corps des sujets recommandables, également propres à dresser le canevas comme à le remplir. On jugera de l'état florissant où elle se trouve par le petit nombre d'observations dont elle est l'objet: c'est la meilleure preuve qu'on puisse alléguer sur le mérite d'une institution de cette espèce. ${ }^{100}$

D'Ecquevilly se contenta de réduire le nombre d'élèves à six, tout en conservant les trois professeurs. Toutefois, les réorganisations du corps des ingénieurs-géographes de juin 1814 et octobre 1817 et la décision d'entreprendre une nouvelle carte de la France (août 1817) eurent pour conséquence une notable réforme de l'école dont le nouveau règlement fut adopté en novembre 1819. La principale mesure portait la durée de la scolarité à deux ans. ${ }^{101}$

${ }^{97}$ Le Dépôt de la Guerre avait déjà publié en 1803 un article de Puissant sur l'Analyse appliquée aux opérations géodésiques’ dans le Mémorial topographique et militaire. En 1808, Sanson mentionnait l'analyse dans la formation des ingénieurs-géographes, qui ont 'passé de longues années dans les écoles pour acquérir l’instruction nécessaire et exigées, instruction qui embrasse: la géométrie, l'analyse, l'astronomie, la physique, la minéralogie, l'art militaire et le dessin’ (SHAT, MR $1978 \mathrm{n}^{\circ} 21$ : cf. n.31). Trente-sept élèves furent admis jusqu'à la Restauration, au cours de promotions variant avec les besoins: quatre élèves en 1809, trois en 1810, six en 1811, trois en 1812, vingt et un en 1813 (dont trois se retirèrent). Si l'on ajoute les ingénieurs sortis de l'Ecole de Prony, tout en retirant ingénieurs et élèves victimes de la réorganisation d'août 1814, on peut estimer à deux douzaines les ingénieurs du début de la Restauration qui avaient reçu une formation mathématique poussée dans ces écoles, soit le tiers des effectifs.

${ }^{98}$ Lettre à Tranchot, 2 avril 1812 (Berthaut, I G., II, 237).

${ }^{99}$ En 1811, un cours de géodésie fut également introduit en seconde année à l'Ecole polytechnique, en lieu et place du cours d'astronomie physique ou d'exposition du système du monde. On y ajouta en 1812-13 des notions générales de géographie physique et d'hydrographie. Il est significatif de noter que sa part ne cessa de accroître sous la Restauration: 3\% du temps en 1812, 8\% en 1818 et 10\% en 1827 (A. Fourcy, Histoire de l'Ecole polytechnique [cf. n.47], pp. 277, 304, 319, 376-9).

100 SHAT, DGG, 2Xa 3: Rapport au ministre de la Guerre, 12 août 1815.

101 AEP, Art. II §3. La rentrée était fixée au $1^{\text {er }}$ janvier et non plus au $1^{\text {er }}$ novembre. 
Les élèves de $1^{\text {ère }}$ année (dite $2^{\text {ème }}$ division) commençaient l'étude de la géodésie. Les leçons portaient sur le $1^{\text {er }}$ volume de la Géodésie de Puissant qui venait d'être refondue en une nouvelle édition. Ils étudiaient ensuite la théorie analytique des projections, selon sa Topographie dont il donna une édition définitive l'année suivante. Ces cours étaient donnés à raison d'une leçon de théorie et d'une leçon d'application de calculs numériques par semaine. De même, leurs camarades de seconde année (ou $1^{\text {ère }}$ division) recevaient deux leçons hebdomadaires, théorique et pratique, de calculs astronomiques, selon le second volume de la Géodésie de Puissant. Deux fois par semaine, ils allaient suivre le cours de géologie de l'Ecole des Mines, ce qui atteste de l'importance croissante de cette discipline.

Avant les cours, les élèves des deux divisions avaient des leçons d'équitation. Enfin, hors des leçons de géodésie ou de géologie, ils devaient consacrer leur temps 'au dessin de la carte, du paysage et de l'écriture moulée', ainsi qu'à 'la lecture d'ouvrages de fortification, d'art militaire et de géographie'.

Comme dans l'école impériale, les opérations sur le terrain se déroulaient en été sous la direction du chef des études, Puissant, et la surveillance d'un de ses collègues. ${ }^{102}$ Les élèves travaillaient sur un canevas rattaché à celui de la nouvelle Carte de France, les nouveaux levant à la planchette au 1/5000 et leurs aînés, à la boussole au $1 / 10$ 000. Selon les recommandations de la grande commission topographique de 1802, le relief était figuré en hachures, et non selon la méthode des courbes de niveaux, utilisée par Du Carla et DupainTriel, préconisée par Lacroix, et dont l’usage commençait de se répandre dans le Génie militaire.

Fait significatif de l'accroissement de son influence, Puissant lui-même interrogeait dorénavant les élèves, en juin, en présence du Comité du Dépôt de la Guerre et des autres professeurs auxquels étaient présentés les travaux réalisés en bureau. En février un nouvel examen portait sur les travaux effectués sur le terrain et achevés en bureau. ${ }^{103}$

Sous la férule de Puissant jusqu'en 1830, l'école d'application devint le principal instrument de professionnalisation de la géographie. Mais le Dépôt de la Guerre s'était doté dès 1802 d'un journal, le Mémorial topographique et militaire, autre mode de transmission du savoir et de cohésion de la profession.

\section{La diffusion des connaissances: Le Mémorial du Dépôt général de la Guerre}

Comme l'École Polytechnique, les Ponts et Chaussées ou les Mines, le Dépôt général de la Guerre souhaita en effet posséder son journal, destiné à une diffusion interne aussi bien qu’à la liaison avec les autres institutions scientifiques ou militaires. Pascal-Vallongue, adjoint d'Andréossy et de Sanson de 1801 à 1803, faisait fonction de rédacteur et joua un rôle moteur dans cette revue qui périclita après soir départ. ${ }^{104}$

${ }^{102}$ Le dossier de pension de Puissant (SHAT, $\mathrm{X}^{\mathrm{em}}$ 176) fournit la liste des travaux géodésiques des élèves qu’il dirigea en région parisienne, normalement de juillet à octobre inclus: Montmorency (1810), St Germain en Laye (1811), Montgeron (1812), Essonne (1813), Melun (août à novembre 1814), Luzarches (juin à septembre 1816), Montmorency (1817), Sceaux (1818), Pierrefitte (1819), Pontoise (1830), Corbeil (1821), Etampes (1822), Beauvais (1823), Rambouillet (1824), La Ferté sous Jouarre (1825) et Mantes (1826).

${ }^{103}$ La place de Puissant était telle que l'on ne jugeait plus nécessaire d'imprimer le programme de l'école, puisque ses traités 'servent en général de texte aux leçons du professeur, et que toutes les théories qui s'y trouvent développées sont obligatoires' (Ecole d'application du Corps royal des ingénieurs géographes-Cours de géodésie et de topographie, AEP, Art. II \3). Par ailleurs, il fut le principal représentant des ingénieurs-géographes au Conseil de perfectionnement de Polytechnique, avec onze sessions: 1809, 1811, 1812, 1816 à 1818, 1820, 1823 à 1826.

104 Voir la liste de ses contributions dans l'Annexe 7.7. 
Si le premier numéro du Mémorial topographique et militaire parut en septembre 1802, alors que Sanson était directeur, l'idée remontait à l'époque de son prédécesseur, puisque dès le 4 novembre 1801 le ministre de la guerre Berthier avait formulé un souhait à ce sujet dans un rapport aux Consuls:

Il serait utile de réunir les écrits qui se rédigent au Dépôt de la Guerre, principalement destinés à l'instruction, dans un volume in- $8^{\circ}$, de 200 à 300 pages, qui serait le premier d'un ouvrage périodique, que le Dépôt pourrait fournir tous les trois mois et qui contiendrait par la suite, selon l'intention du Premier Consul, les principales reconnaissances militaires, les faits de guerre dont l'authenticité serait constatée et dont la publication serait approuvée par le gouvernement. ${ }^{105}$

Ainsi, dès l'origine apparaît le double but de l'organe du Dépôt de la Guerre: un but pédagogique intéressant principalement le corps et un but d'information externe, qui semblait avoir les faveurs du pouvoir. L'échec de l'entreprise, du moins dans sa périodicité, était contenu en germe dans ces objectifs. En effet, les reconnaissances militaires ne pouvaient se limiter au seul intérêt historique et géographique. Leur caractère même rendait leur diffusion malvenue pour le pouvoir, surtout après la rupture de la paix d'Amiens. ${ }^{106}$ Quant aux travaux théoriques destinés à l'instruction, ils ne justifiaient certes pas une parution régulière aussi rapprochée. Il n'en reste pas moins qu'ils constituèrent bien la charpente de la première publication périodique consacrée à la cartographie. ${ }^{107}$

Sept numéros seulement parurent jusqu'en 1810. La suite, avec une seconde édition refondue sous le nom de Mémorial du Dépôt général de la Guerre, ne fut donnée qu'à partir de $1825 .{ }^{108}$ Seuls les cinq premiers, parus en un an, de septembre 1802 à septembre 1803, respectèrent à peu près les échéances prévues. Le numéro 6 sortit vingt-et-un mois plus tard, en 1805. Le dernier, paru en 1810 sous la forme d'un ouvrage autonome faisant suite au Mémorial, est en fait un traité sur la projection adoptée par le Dépôt qui vient compléter les ouvrages de Puissant au programme de l'Ecole nouvellement créée. Au reste, chacun des numéros antérieurs privilégiait également un aspect: les numéros impairs, intitulés Topographie, traitaient plus particulièrement de théorie ou de l'état de la topographie tandis que les numéros pairs, Historique, avaient un caractère militaire ou de géographie descriptive plus prononcé. Enfin, en s'espaçant, les numéros devenaient plus volumineux et moins vulgarisateurs.

105 MDGG, I (1829), 3.

${ }^{106}$ La publication des reconnaissances militaires n'était sans doute pas plus souhaitable que celle de certaines cartes. La décision de la mise sous scellés de la carte d'Egypte fut prise par Napoléon à Bayonne, le 14 mai 1908, en marge d'un rapport de Clarke daté de la veille (IGN, archives anciennes, carton 1762-1869). La carte de la Morée, achevée à la même époque, subit le même sort (Berthaut, I.G., I, 277-8 et II, 396).

${ }^{107}$ Rappelons que le Mémorial faisait partie des ouvrages officiels de l'Ecole d'application en 1809.

108 Le général marquis Delachâsse de Vérigny, directeur du Déprit, obtint le 19 mai 1824 l'autorisation de reprendre la publication du Mémorial, dont le $\mathrm{n}^{\circ} 8$ de 1825, fut publié en 1826. Le 12 août 1826, la réimpression des sept premiers numéros fut autorisée: dans une édition refondue et annotée, ils formèrent les volumes I (1829) et II (1831) de la revue (cf. n.124). 
Un comptage rapide de la surface montre l'importance accordée à la géographie $(92,9 \%)$-surtout à la cartographie (60,6\%) (voir Annexe 7.7.).

\author{
Vie du Dépôt de la Guerre et du Mémorial \\ Information sur la production cartographique \\ Théorie et pratique de la géodésie/topographie \\ Projection des cartes \\ Conventions cartographiques \\ Gravure \\ Géologie \\ Aspects militaires de la géographie \\ Descriptions géographiques \\ Histoire et art militaires
}

$$
\begin{array}{r}
\% \\
3,7 \\
8,5 \\
24,0 \\
17,0 \\
5,9 \\
1,5 \\
3,5 \\
8,7 \\
20,0 \\
7,1
\end{array}
$$

Les aspects scientifiques et techniques représentent un peu plus de la moitié (51,9\%). Les aspects militaires, en revanche, même en rapport direct avec le travail des ingénieurs géographes, occupent moins du sixième de la surface $(15,8 \%)$. Si le Dépôt de la Guerre est bien au service des pratiques politiques et militaires du temps, s'il est bien un instrument du pouvoir, il se présente avant tout comme une institution scientifique méconnue.

Le caractère scientifique de la revue fut même nettement accentué de 1802 à 1810. Dans le premier numéro, une 'Notice sur la construction des cartes géographiques', due au mathématicien Lacroix -et accessoirement au géographe Barbié du Bocage pour la partie historique- traitait du sujet sans utiliser une seule formule mathématique. L'article 'Des opérations géodésiques' de Bonne dans ce même numéro se contentait de développer un seul exemple. Avec la suite, donnée par Muriel dans le numéro 3, 'Des opérations géodésiques de détail', il constituait, somme toute, surtout le mode d'emploi des instruments (cercle répétiteur, planchette, boussole) et fournissait des tables pour réduire les angles. Certains de ces aspects devaient être repris par Allent, ingénieur militaire, secrétaire du Comité central du Génie et membre du Conseil de perfectionnement de l'Ecole polytechnique, naguère attaché au Cabinet topographique du Directoire.

Dans le numéro 5 au contraire, le dernier de 1803, Puissant aborde l'Analyse appliquée aux opérations géodésiques'. Pour lui, la 'méthode très ingénieuse et très exacte' de Dionis du Séjour, répandue et enseignée à l'Ecole des Géographes, 'n'est ni aussi simple, ni aussi directe que le comporte la nature du problème'. ${ }^{110} \mathrm{Il}$ prône celles de Legendre ou de Delambre, 'exemptes de toute objection', et particulièrement la première, qu'il démontre avec précision, parce qu'elle utilise l'arc de cercle et non pas sa

\footnotetext{
${ }^{109}$ Ce comptage rudimentaire par pages a été établi à partir de la seconde édition (seule à présenter un format unique pour tous les numéros) après avoir écarté les additions spécifiques à cette édition.
}

${ }^{110}$ Mémorial topographique et militaire, $\mathrm{n}^{\circ} 5$ (1803), 126-97 (pp. 152-3). 
corde. ${ }^{111}$ Sept ans plus tard, dans son Mémoire sur la projection des cartes géographiques adoptée au Dépôt général de la Guerre faisant suite au Mémorial, le colonel Henry utilisait tout aussi largement le langage mathématique et les travaux de Legendre. ${ }^{112}$

L'analyse faisait ainsi une entrée en force dans le Mémorial avant même d'être introduite à l'école impériale des ingénieurs-géographes, malgré la mention favorable dont elle avait fait l'objet dans le projet d'instruction mathématique de 1802. Son importance croissante représente surtout l'aboutissement des efforts de Puissant. Depuis longtemps, il était l'un des hommes les plus habitués aux formules et aux procédés de la trigonométrie' et il avait été marqué par les cours de Lagrange et Fourier et par l'oeuvre de Legendre. ${ }^{113} \mathrm{Au}$ même moment, en Savoie, Nouet répugnait à faire de la triangulation et préférait se contenter de multiplier les observations astronomiques, comme il l'avait fait en Egypte. ${ }^{114}$ Deux époques commençaient à se confronter: l'ancienne, dans laquelle les astronomes travaillaient en complémentarité avec les géomètres arpenteurs, et la nouvelle où Puissant et les ingénieurs issus de Polytechnique se dotaient des outils de la cartographie française du XIX ${ }^{\mathrm{e}}$ siècle.

\section{Conclusion}

De ce survol de la période révolutionnaire et impériale, on retiendra deux points marquants.

C'est d'abord la naissance d'une profession, sensible quantitativement et qualitativement. En 1789, les ingénieurs-géographes militaires ne formaient guère qu'un petit groupe d'une vingtaine d'éléments, assez hétérogène et en voie d'extinction. En 1814, ils forment un corps structuré, plus nombreux -une centaine- et de plus en plus homogène, grâce au renouvellement des effectifs assuré par une formation unique, dont le niveau s'est élevé en suivant l'évolution de la recherche mathématique. A ce sujet, il serait souhaitable que les travaux de Puissant et son rôle à l'école d'application des ingénieurs géographes fassent l'objet d'une étude affinée. Mais ce phénomène est particulièrement caractéristique: sur le modèle de Polytechnique et en liaison avec elle, enseignement et recherche sont dorénavant étroitement liés, avec le pouvoir étonnamment étendu de Puissant, tout à la fois auteur des manuels en usage, professeur, examinateur en cours d'études et à la sortie de l'école, et membre du Conseil de perfectionnement de Polytechnique responsable du programme.

111 Contrairement aux affirmations de Puissant, les méthodes de Legendre et Delambre ne semblent pas avoir été encore très répandues en 1803 chez les ingénieurs chargés des opérations géodésiques de premier ordre (Ibidem). La même année, en revanche, il vérifia personnellement par la méthode publiée par Legendre en 1799 un calcul de coordonnées que Méchain avait fait à l'île d'Elbe (Berthaut, I.G., I, 406). Pour sa part, Nouet utilisait la méthode de Dionis du Séjour (Delambre, art. 'Nouet', Biographie universelle (Michaud) ancienne et moderne, nouv. éd., (Paris-Leipzig), s.d., t.31).

112 Maurice Henry (1763-1825) avait été directeur de l'observatoire de Mannheim puis de celui de l'Académie de SaintPétersbourg avant de devenir directement colonel ingénieur-géographe du Dépôt de la Guerre (juin 1801). Quelques titres de chapîtres montrent assez le caractère de son mémoire: 'Expressions analytiques de quelques parties d'un sphéroïde de révolution' (Chapitre II), 'Expression, analytiques des mêmes parties du sphéroïde que l'on veut considérer, en fonction de la latitude vraie' (Chapitre III), 'Développements en séries régulières des formules du Chapitre III’ (Chapitre V).

${ }^{113}$ Parisot, art. 'Puissant', Biographie universelle (Michaud) ancienne et moderne, nouv. éd., (Paris-Leipzig). s.d., t.34.

114 Berthaut, I.G., I, 364-5. Pour l'Egypte, voir l'excellent travail d'Anne Godlewska, 'The Napoleonic Survey of Egypt. A Masterpiece of Cartographic Compilation and Early Nineteenth-Century Fieldwork', Cartographica, 25, 1 et 2: monograph 38-9 (1988). 
Enfin, si la géographie 'ça sert d'abord à faire la guerre' et si les ingénieurs-géographes ont bien été des instruments essentiels de la géopolitique du pouvoir; s'ils ont d'ailleurs parfaitement rempli leur mission en ce domaine, il est clair que là n'était pas le principal centre d'intérêt des autorités du corps. Les préoccupations permanentes du Dépôt général de la Guerre, ses liens avec la communauté scientifique, les programmes de l'Ecole d'application et le contenu du Mémorial mettent tous largement l'accent sur les aspects scientifiques de la profession de préférence à ses aspects militaires. Ceux-ci constituent avant tout pour les ingénieurs géographes le cadre institutionnel favorable qui leur assure un champ d'action plus large et une reconnaissance sociale. La reconnaissance de la communauté scientifique, sensible dans l'intérêt que Lacroix ou Laplace portaient aux travaux du Dépôt, sera confirmée avec éclat par l'élection de Puissant au siège de ce dernier à l'Académie des Sciences le 3 novembre 1828.

\section{Annexes}

\subsection{Instructions du général Meunier, 2 janvier $1799^{115}$ \\ Connoissances à exiger des élèves \\ qui se destinent au service d'ingénieurs géographes artistes aux armées attachés au département de la Guerre}

Instruction pour les élèves

Le service des ingénieurs géographes tant aux armées que sur les côtes et frontières, exige indispensablement.

$1^{\circ}$ d'avoir l'acquit en géométrie jusques et compris au moins la trigonométrie rectiligne;

$2^{\circ}$ de dessiner facilement la carte tant à la plume qu'au lavis, mais surtout à la plume et faire l'écriture moulée;

$3^{\circ}$ d'écrire assés correctement pour former des mémoires locaux et des observations sur les parties de pays dont ils auront fait les reconnoissances militaires ou les cartes levées méthodiquement.

Il seroit très utile que ces ingénieurs sçussent les principes de la perspective et qu'ils dessinassent facilement le paysage car il y a nombre de circonstances ou la vue d'un siège, d'un assaut, d'une bataille, ou seulement d'un site intéressant sous quelque raport devient d'un grand secours pour l'intelligence d'une carte si bien qu'elle puisse être rendue.

Il est indispensable que les ingénieurs soient en état de faire des nivellemens plus ou moins étendus puisque ce n'est que par ce secours qu'on peut calculer les déblais et les remblais déterminer la pente à donner à un canal d'arrondissement de moulin ou de navigation et exécuter ce qui peut être relatif à la fortification passagère.

\footnotetext{
115 SHAT, MR 1978 n 35, daté et corrigé de la main de Meunier. Un autre exemplaire (n 25) porte sa seule signature.
} 
Instruction matérielle

pour ingénieurs géographes et artistes de $1^{\text {ère }}$ et $2^{\mathrm{e}}$ Classe

\section{Modèles de la carte uniformes}

Persuadé qu'il n'est pas indifférent d'établir autant que l'on peut de l'uniformité dans la manière de rendre ou exprimer les différents terreins dont on fait la carte, il devient donc absolument nécessaire qu'aumoins chaque chef de section ait un modèle de dessin de carte partant du centre commun (le Dépôt de la Guerre) ces modèles seroient dessinés tous dans la même proportion et sur l'échelle adoptée soit pour les cartes militaires soit pour la continuation de la Carte des côtes et frontières de la République ou autres.

\section{Nature du pays}

Avec cette attention on pourroit accoutumer les yeux à voir à peu près tous la même manière, car j'ai connu tel ingénieur qui voyoit partout des montagnes ou tel autre ne voyoit que des plaines et ne comptoit pour montagne que celles réellement difficiles à gravir.

Dans toutes les cartes mais surtout dans celles militaires il est bien important que les ondulations un peu sensibles y soient exprimées, puisque cela détermine l'officier général sur la disposition d'un camp ou sur toute autre opération.

\section{Echelles pareilles}

II est nécessaire que tous les ingénieurs ayent chacun une échelle parfaitement uniforme, en sorte qu'elles soient volontiers tracées d'un même trait de pointe afin de faciliter les raccordements des différents morceaux qui doivent se réunir.

\section{Adoption au choix d'instrumens}

Quant à l'usage de tel ou instrument, il convient que les ingénieurs sachent également se servir de tous. La planchette réunit plus de certitude au moment même; la boussolle est plus expéditive sur le terrain et moins embarassante, il en est de même du graphomètre; mais ces deux derniers laissent un travail de cabinet; quelquefois des cottes oubliées et l'obligation de dessiner des brouillons pour les rapporter. C'est à l'ingénieur à faire son choix suivant le tems la nature du pays et les circonstances.

Chaque ingénieur enverra tous les mois au directeur général, avec le bulletin décadaire un huilé représentatif, pris sur une carte gravée convenue de l'état progressif de son travail pendant le mois échu.

\section{Inspection du chef}

Le chef de section devra de tems à autre faire une tournée pour voir le travail effectif de chacun des ingénieurs, en connoître le progrès, ainsi que la conduite particulière et privée de chacun des ingénieurs, en connoître les progrès, ainsi que la conduite particulière et privée de chacun d'eux [sic]. Il leur fera amicalement ses observations sur ce qui paroîtra l'exiger -particulièrement sur leur travail; mais avec la condition d'informer le directeur du motif d'éloge ou de blâme. Ces ingénieurs en faisant leur travail topographique recueilleront tous les renseignements possibles pour former les mémoires relatifs à ce qu'ils auront levé.

\section{Nottes pour les mémoires}

Ces mémoires devront être différents selon qu’il seront ou militaires ou seulement locaux. 
Les ingénieurs prendront des renseignemens sur les cartes qui peuvent être plus ou moins intéressantes soit manuscrites, ou gravées, pour en procurer l'acquisition au Dépôt de la Guerre ou des copies qu'ils feront.

\section{Notions sur les approvisionnements}

II sera bon que chaque ingénieur sçache calculer par la forme des approvisionnements ce qu'une meule de bled ou de foin peut contenir, ainsi qu'une grange, cour, grenier, qu'il évalue par apperçu le produit d'une prairie en verd. Qu'enfin il sçache appliquer ses principes de géométrie à tous les cas possibles.

\section{Rédaction des cartes, plans et mémoires}

Après avoir réuni tout son travail et selon les ordres qu'il aura reçu chaque ingénieur devra se rendre soit au Quartier Général, ou autre lien ou au Dépôt de la Guerre pour y finir la minute du terrain qu'il aura levé, en faire le raccordement avec le travail de ceux de ses confreres qui sont contigus et rédiger son Mémoire particulier. Chaque chef de section réunira plusieurs mémoires pour en faire un général et sommaire; en sorte que l'officier supérieur puisse s'en servir utilement étant élagué des objets de détails qui ne deviennent utiles que subsidiairement.

\section{Paris, 13 nivôse an 7}

Le général de brigade directeur du Dépôt général de la Guerre

$$
\text { /:/ Meunier }
$$

7.2. Extraits du Sommaire du travail du Dépôt général de la Guerre, par Pascal-V allongue, septembre 1801 à février $1802^{116}$

[Vendémiaire an 10]:

L'instruction des élèves admis par la faveur du directeur [précédent, le général Clarke] était à peu près nulle, sans principes ni élémens positifs. [...] Le nombre des élèves a été complété et leur instruction reprise au moyen d'un cours de mathématiques commencé par le citoyen Moynet et des leçons de dessin et lavis de cartes données parle citoyen Béraud.

[Brumaire an 10]:

Le citoyen Bacler d'Albe chargé par le général directeur [Andréossy] de professer la topographie aux élèves du Dépôt a commencé ses leçons le 2 brumaire pour les continuer les 4 et 6 de chaque décade. Après leur avoir donné quelques notions élémentaires sur la géographie phisique, il leur a expliqué succinctement la théorie des projections et son application à la géographie linéaire. Quelques notions sur l'optique et sur la perspective ont précédé les principes théoriques du dessin géométral et du dessin en perspective d'où il a déduit les diverses manières de dessiner la topographie, en les appréciant et donnant la préférence à celle qui se fonde sur les projections horizontales comme n'offrant que de légères imperfections au milieu des nombreux avantages.

116 SHAT, DGG, 2X 3 3. Le compte-rendu des cours ne représente qu'une faible part du Sommaire, lequel forme chaque mois un cahier manuscrit de quelques pages. Sa tenue déclina vite et il cessa sans doute avant même le départ d'Andréossy, ce qui nous prive d'une source originale. 
Quant au cours de mathématiques, le citoyen Moynet qui en est chargé a montré aux élèves l'usage des tables de logarithmes et celui des divers cercles relatifs à la géographie; et en continuant l'explication de la sphère et du globe terrestre, il a entrepris le cours de géométrie. Quelques élèves plus instruits répètent ces leçons à ceux qui commencent, et le citoyen Béraud suit particulièrement leur instruction, sous la surveillance du citoyen Hervet.

[Frimaire an 10]:

Le $C^{\text {en }}$ Moinet a continué d'expliquer aux élèves [les] éléments de géométrie, jusqu'aux surfaces, ainsi que les différens cercles de la sphère.

Le $\mathrm{C}^{\mathrm{en}}$ Dalbe a continué de leur donner des leçons sur la manière d'exprimer la topographie et de rendre sensible soit [sic] une surface plane l'aspect et le relief du terrein.

[Nivôse an 10]:

L'instruction des élèves a porté en géométrie sur les surfaces et l'application de la sphère et des questions de géographie. Les leçons de topographie on été momentanément remplacées, à cause de la rigueur de la saison, par un cours de perspective théorique et pratique. On a vu dans le courant du mois les principes du tracé des plans perspectifs réguliers, irréguliers et de forme ronde.

[Pluviôse an 10]:

L'instruction des élèves a eu pour objet la trigonométrie rectiligne, la réduction des angles, et les principes du tracé des plans perspectifs; un problème de perspective a été donné mais non résolu par incapacité et par negligence.

7.3. Ordre du général Andréossy, 30 mars $1802^{117}$

Ordre du général directeur

du 9 germinal an 10

concernant un exercice propre à faire reconnoître les élèves capables d'être employés en campagne

Les élèves que leurs connoissances en trigonométrie rendent capables d'opérer sur le terrein, y seront exercés sous la direction du $C^{\mathrm{en}}$ Moynet.

Il leur sera donné dans la décade prochaine un terrein à lever tel qu'ils ayent à y mesurer une base, à y établir une première triangulation avec le graphomètre ou le sextant et à y trouver à résoudre dans les détails tous les problèmes de planchette et de boussole.

Le $\mathrm{C}^{\mathrm{en}}$ Moynet après avoir lui-même levé et reconnu les principaux points pour servir de vérificateurs, leur expliquera en détail les méthodes et les procédés dont ils devront se servir, leur donnera les distances d'un ou plusieurs points à la Méridienne et à la perpendiculaire de Paris afin qu'ils y rapportent les sommets de leurs triangles; mais il les laissera opérer, calculer et rapporter eux-mêmes.

Les quatre ou cinq élèves au plus qui seront admis à ce concours sur la désignation des $C^{\text {ens }}$ Hervet, Dalbe et Moynet rapporteront leur minute sur l'échelle de 1 centimètre

117 SHAT, DGG, reg. 8, vendémiaire an 9 à prairial an $10, \mathrm{n}^{\circ} 539$. 
pour 100 mètres et la réduiront pour le mis au net à celle de 5 millimètres pour 100 mètres, ils en dessineront et laveront la carte, qu'ils seront tenus de remettre au Cit ${ }^{\mathrm{n}}$ Hervet du 12 au $15 \mathrm{du}$ mois prochain.

Ils accompagneront cette carte d'un mémoire raisonné, sur les méthodes, procédés et instruments qu'ils auront employé pour opérer, pour établir leurs calculs, et pour exprimer le figuré du terrein; ils y énonceront en outre la nature de ce terrein, sa latitude et longitude, sa température pendant le tems de l'opération; ses plantations, cultures et produits, sa population, ce que des établissements publics ou particuliers peuvent offrir de remarquable, sa position sous les rapports administratifs, sa distance relative aux principaux lieux du voisinage; l'état et la direction des routes et sentiers qui le traversent; de ses cours d'eaux, et fontaines, leur source, leurs variations aux diverses saisons, la nature des eaux, l'usage qu'on en fait, les mines ${ }^{118}$ qu'elles font mouvoir, les ponts, gués, bacqs qu'on trouve sur leurs cours dans un arrondissement limité; et enfin quelques traits historiques ou militaires qui peuvent avoir rapport aux localités.

Ce travail sera jugé par les $C^{\text {ens }}$ Dalbe, Hervet et Moinet, en présence du Général Directeur, qui classera d'après le mérite d'un chacun les droits qu'il aura d'être envoyé en campagne, et décernera aux deux concurrents qui auront le mieux réussi, soit quelque ouvrage, soit quelque instrument utile, à titre d'encouragement.

Le $C^{\text {en }}$ Hervet est chargé de surveiller l'exécution du présent ordre, qui est spécialement confié au $C^{\text {en }}$ Moynet.

\section{Le général directeur du Dépôt}

\subsection{Projet de cours de mathématiques, sans date $(0.1802)^{119}$}

Instruction des élèves ingénieurs géographes

\section{Mathématiques}

Les élèves ingénieurs géographes destinés à se transporter sur le terrain pour en figurer la topographie, ont besoin de connoissances mathématiques pour remplir leurs fonctions avec succès.

Le partage des terres après la retraite du Nil, donna naissance à la géométrie, chez les Egyptiens; il est aisé de se convaincre en effet qu'il est impossible de faire la moindre opération sur le terrain sans avoir recours à la géométrie.

Il est vrai que les connoissances géométriques, nécessaires à la levée des plans sont assez bornées; la pratique seule peut suffire à la rigueur. Mais quel est l'ingénieur, ami de son état, qui voudroit se borner à une simple profession méchanique. Avec la pratique seule les plus légers obstacles arrêtent; avec une théorie solide, les idées se lient, s'étendent et fournissent des moyens ingénieux de vaincre les difficultés.

Il seroit superflu d'insister sur la nécessité d'étudier la géométrie spéculative. L’ingénieur figurant le terrain à la planchette, peut s'en passer, lorsqu'il a des points de départ exactement déterminés; mais ces points exactement déterminés ne peuvent lui être donnés que par la mesure des angles avec des instruments, et s'il faut qu'il les détermine lui-même, il doit connoitre les principes de la résolution des triangles pour en conclure les cotés; car la pratique ici seroit très défectueuse, lorsque les cotés ont une assez grande étendue, il est indispensable de les calculer.

118 Mauvaise transcription du copiste pour: 'usines'.

119 SHAT, MR $1978 \mathrm{n}^{\circ} 22$ 
Il est donc nécessaire que les ingénieurs géographes étudient la géométrie et la trigonométrie rectiligne et surtout cette dernière qui n'est qu'un corollaire de la théorie des triangles en géométrie et qui donne les moyens de les resoudre par le calcul. La trigonométrie sphérique sans être indispensable pourra devenir utile, soit pour la réduction des angles à l'horison, soit pour être en état d'étendre les principes sur lesquels sont fondées les différentes projections employées dans la géographie. Car suivant la qualité de géographe ajoutée à celle d'ingénieur, toute la Terre est leur domaine et ils doivent savoir représenter des fractions plus ou moins grandes de sa surface et même sa totalité.

Jusques là les mathématiques élémentaires suffisent à l'ingénieur, mais s'il s'agit de former sur le terrain des triangles de 10. à 12. lieues de cotés, propres à établir le canevas d'une carte, s'il veut déterminer une méridienne pour rapporter ses triangles à cette méridienne et à sa perpendiculaire, en faisant dans ses calculs abstraction de la sphéricité de la Terre, il aura besoin alors des mathématiques transcendantes, s'il veut dumoins se rendre compte des méthodes qu'elles enseignent pour parvenir plus surement aux résultats qu'on vient de citer. Ces opérations jusqu'à présent ont été attribuées à des ingénieurs astronomes, mais lorsqu'elles ont pour objet de connoitre la topographie détaillée d'un pays, il semble qu'elles devroient appartenir aux ingénieurs géographes. Nous convenons cependant que ces connoissances ne peuvent être l'objet d'une première instruction; il est essentiel d'abord de former des sujets propres à remplir les fonctions attribuées jusqu'à ce jour aux ingénieurs géographes; en se reservant par la suite d'étendre leur instruction et de l'appliquer aux opérations géodésiques.

D’après cet exposé le cours de mathématiques que devront suivre les élèves ingénieurs géographes, sera composé, savoir:

$1^{\circ}$ de l'arithmétique. La science des nombres est nécessaire à tous les hommes, elle est indispensable aux ingénieurs pour les calculs trigonométriques. Le calcul décimal y sera développé avec la plus grande étendue et appliqué aux mesures républicaines; cette partie sera terminée par la théorie et l'usage des logarithmes.

$2^{\circ}$ de la géométrie. On insistera particulièrement sur la théorie des triangles, sur la mesure des surfaces, le toisé. On fixera l'attention des élèves, sur les rapports des nouvelles mesures de surfaces et de capacités avec les anciennes, rapports qu'on n'aura pu faire connoître suffisament dans l'arithmétique.

$3^{\circ}$ de la trigonométrie rectiligne. Les élèves seront spécialement appliqués à la théorie des sinus et à l'usage des tables, on terminera cette partie en indiquant les différens procédes employés dans le nivellement.

$4^{\circ}$ de la trigonométrie sphérique.

$5^{\circ}$ des élémens de l'algèbre. Cette partie sera poussée jusqu'aux équations du second degré inclusivement. Ces connoissances suffisant pour passer à l'application de l'algèbre à la géométrie et même aux sections coniques.

$6^{\circ}$ de l'application de l'algèbre à la géométrie. C'est ici que les élèves généraliseront leurs idées. Ils reconnoîtront que la synthèse qu'on aura employée dans les démonstrations géométriques n'est pas la méthode la plus simple, qu'elle marche pésamment et qu'elle particularise presque toujours les questions; qu'au contraire l'analyse les généralise, qu'elle éxige souvent moins d'effort d'esprit, qu'elle est plus expéditive et presque toujours plus élégante.

$7^{\circ}$ d'un traité des projections géographiques. 
7.5. Règlement de l'Ecole impériale des ingénieurs-géographes, 30 octobre $1809^{120}$

Réglement général d'instruction pour

l'Ecole impériale des ingénieurs géographes

Titre $1^{\mathrm{er}}$

Du personnel de l'école

\section{Article per}

L’Ecole impériale des ingénieurs géographes sera établie au Dépôt général de la Guerre sous le commandement de l’officier général, directeur de cet établissement.

$2^{\circ}$ L'enseignement sera exclusivement confié à des ingénieurs géographes.

(a) Il y aura: un professeur de mathématiques appliquées;

(b) un professeur de dessin de la carte;

(c) un professeur de paysage et de gravure.

Ces professeurs seront nommés par le ministre de la Guerre, sur la présentation de l’officier général directeur.

Ils pourront être choisis parmi les ingénieurs réformés, qui jouiront dans ce cas d'un traitement supplémentaire.

$3^{\circ}$ Une Commission d'instruction sera chargée d'examiner, au moins tous les trois mois les progrès des élèves et de présenter à la fin de chaque année un rapport au ministre de la Guerre sur les améliorations à faire dans toutes les parties de l'instruction.

Cette commission présidée par l’officier général directeur sera composée:

(a) des trois professeurs;

(b) d'ingénieurs géographes qui seront désignés au commencement de chaque année par cet officier général qui tient registre des délibérations de la commission.

Titre 2

De la police

$4^{\circ}$ Les élèves seront tenus d'être présens au Dépôt général de la Guerre, tous les jours, depuis 9 heures du matin, jusqu'à 4 heures du soir, les fêtes et les dimanches exceptés.

Ils seront sous la surveillance immédiate d'un des professeurs, et seront soumis à la discipline militaire.

$5^{\circ}$ L'exclusion de l'école sera prononcée par le ministre sur le rapport de la Commission d'instruction.

Titre 3

De l'instruction et de l'emploi du tems

$6^{\circ}$ Les élèves recevront à l'Ecole le complément de leur instruction dans le cours d'une année.

$7^{\circ}$ Le programme déjà adopté par le Conseil de perfectionement de l'Ecole impériale polytechnique pour l'instruction des ingénieurs géographes, sera la base de l'enseignement.

Les additions ou changemens que la Commission d'instruction pourroit proposer de faire à ce programme, seront soumis à la discution de ce conseil.

120 SHAT, MR 1978 n 110. Clarke avait été fait comte de Hunebourg par Napoléon en 1808. 
$8^{\circ}$ Pendant les premiers 6 mois de séjour à l'école et à dater du 1er novembre, les élèves s'occuperont sans interruption de la théorie et de la pratique des calculs géodésiques, du dessin topographique et du paysage. Ils feront en outre des essais de gravure à l'eau forte et de plans reliefs.

Ils recevront trois fois par semaine des leçons sur chacune de ces diverses parties.

$9^{\circ}$ Les époques auxquelles ils devront se livrer aux exercices d'équitation seront indiquées par le directeur.

$10^{\circ}$ Les occupations journalières seront réglées comme il suit [voir Tableau 1].

$11^{\circ}$ Pendant les mois d'août, septembre et octobre, les élèves seront distribués en une ou deux brigades et envoyés en campagne tant pour faire des applications de la trigonométrie et du nivellement, que pour s'habituer à figurer le terrein au moyen des instrumens et à l'aide du seul coup d'oeil.

$12^{\circ}$ Chaque brigade sera commandée par un des professeurs chargé de diriger en même tems les opérations des levés, suivant le plan qui aura été adopté par la Commission d'instruction.

Chacun des individus composant une brigade recevra une indemnité de campagne.

$13^{\circ}$ Pendant le dernier trimestre des études, les élèves feront les calculs, ainsi que les mises au net de leurs opérations sur le terrein, et rédigeront d'après des programmes arrêtés par la Commission d'instruction divers mémoires sur les travaux géodésiques, militaires et statistiques.

Les cours seront mis en activité et l'on y fera principalement le résumé des théories et de leurs applications les plus importantes.

$14^{\circ}$ Les élèves seront exercés aux observations astronomiques pendant leur séjour à l’ Ecole.

$15^{\circ}$ Les ouvrages adoptés pour l'instruction des élèves sont, le Mémorial du Dépôt général de la Guerre et les traités de Géodésie et de Topographie de $\mathrm{M}^{\mathrm{r}}$ Puissant. Du reste, chaque professeur, en ce qui le concerne, se conformera aux dispositions du programme d'instruction cité à l'article 7.

Titre 4

Examen pour la sortie de l'école

$16^{\circ}$ Dans les derniers jours d'octobre, chaque élève sera examiné en présence de la Commission d'instruction.

Cet examen sera confié à un jury composé du directeur général du Dépôt de la Guerre ou de son adjoint et de deux officiers supérieurs du corps qui seront désignes par le ministre.

Ce jury formera la liste de mérite qui règlera le rang de promotion.

\section{L'examen roulera}

$1^{\circ}$ Sur la conduite, le zèle et l'intelligence de chaque élève pendant tout le tems qu'il aura passé à l'Ecole.

$2^{\circ}$ Sur le travail qu'il aura fait dans les diverses parties de l'enseignement et dont il rendra compte lui-même.

Les examens relatifs aux connoissances ne pourront porter que sur les matières énoncées dans le programme d'instruction mentionné à l'article 7 et ne faisant point partie de celles qui sont enseignées à l'Ecole impériale polytechnique.

Les élèves qui n'auront pas satisfait à la première partie de l'examen [seront] déclarés inadmissibles. 
Tableau 1. La distribution des études et de l'emploi du tems pendant une année.

\section{De novembre à avril}

Du lundi au samedi

De $9 \mathrm{~h}$ à $11 \mathrm{~h}$ : Mathématiques

De 11 h à 4 h : Dessin

\section{De mai à juillet}

Du lundi au samedi

De $9 \mathrm{~h}$ à $11 \mathrm{~h}$ : Mathématiques

De $11 \mathrm{~h}$ à $1 \mathrm{~h}:$ Dessin

Lundi, mercredi et vendredi

De $1 \mathrm{~h}$ à $4 \mathrm{~h}$ : Paysage

Mardi, jeudi et samedi

De 1 h à 4 h : Gravure

\section{D'août à octobre}

Ces trois mois sont employés sur le terrein.

\section{Observations}

Les mois d'août, septembre et octobre seront employés sur le terrein.

Les levés se feront à l'échelle du 10 / 1000.

Les reconnoissances à l'échelle du 20 / 1000.

Les examens de la commission se feront tous les trois mois à dater du 15 novembre de chaque année.

L'examen du jury pour l'admission commencera le 15 février de chaque année.

Les leçons ou les exercices mentionnés dans ce tableau ne pourront être suspendus que quand les élèves feront des observations astronomiques. 
Ceux qui ayant satisfait à la $1^{\text {ère }}$ partie de l'examen ne satisferont pas complettement à la seconde pourront être admis à rester un an de plus à l'Ecole et pourront être envoyés pendant cette année à un bureau topographique sous la surveillance particulière de l'officier commandant, après quoi ils subiront un nouvel examen.

Ceux qui auront entièrement satisfait aux deux parties de l'examen seront admis et classés suivant l'ordre de leur mérite.

En conséquence du tems consacré par les élèves à leur instruction, il sera reconnu à chacun d'eux trois années de service d'officier à l'instant où il entre en cette qualité dans le corps.

Paris, ce 30 octobre 1809

Le ministre de la Guerre

Comte d'Hunebourg 
7.6 Programme de l'Ecole impériale des ingénieurs-géographes, $1809^{121}$

[Programme de l'instruction spéciale

que recevront les élèves de l’Ecole impériale des ingénieurs géographes, établie au Dépôt général de la Guerre] ${ }^{122}$

[Nota. Les matières que ce programme renferme et qui sont enseignées à l'Ecole impériale polytechnique, ou que la lecture seule peut faire ne feront point partie des leçons données à l’Ecole des ingénieurs géographes].

Instruction spéciale donnée à l'Ecole d'application et arrêtée par le Conseil de perfectionnement dans sa session de l'an 1809

\section{(1) Théorie}

(A) Trigonométrie

Plusieurs formules des trigonométries rectiligne et sphérique qui concernent les opérations géodésiques et qui ne sont pas dans les cours classiques ordinaires.

(B) Astronomie

(I) théorie de la sphère; exposition abrégée du sistème du monde; mesure du tems; théorie des parallaxes;

(II) les différents moyens

(a) de connoître la marche d'un pendule;

(b) de déterminer les latitudes et les longitudes tant sur terre que sur mer;

(c) d'orienter un plan.

(C) Géodésie

(I) théorie analytique du sphérö̈de terrestre; application de cette théorie à la recherche des formules employées pour calculer les longitudes, les latitudes, les azimuths, les différences de niveau, \&a ;

(II) comment on déduit les dimensions de la Terre des opérations géodésiques;

(III) théorie générale des projections des cartes;

(IV) principes d'après lesquels on trace les fuseaux qui servent à recouvrir les globes;

(V) élémens de perspective.

(D) Physique

(I) théorie des réfractions athmosphériques;

(II) théorie du pendule; conclure l'applatissement de la terre des observations faites en différents lieux avec cet instrument;

${ }^{121}$ IGN, archives anciennes (carton 1762-1869).

${ }^{122}$ Les passages entre crochets sont rayés sur l'original, et remplacés par les passages soulignés. 
(III) théorie du baromètre et son application la mesure des hauteurs; diverses formules barométriques propres cet objet;

(IV) Quelques notions de dioptrique immédiatement applicable à la construction des lunettes.

(E) Géologie

Connoître et distinguer la nature des terres, des pierres, et en général des roches qui se trouvent dans chaque terrein, et que l'on indique sur la carte, soit par des teintes, soit par des caractères adaptés.

(F) [Connoissances militaires]

(I) (Fortifications)

Principes généraux de la fortification permanente et de campagne, de l'attaque et de la défense des costes.

(II) (Manoeuvres)

(a) [d'infanterie];

(b) [de cavalerie].

\section{(2) Pratique}

(A) Opérations sur le terrain

(I) Astronomiques

(a) Mesurer des angles avec le cercle répétiteur, le quart de cercle astronomique, le théodolite, le sextant, le cercle de réflexion, \&a.

(b) Observer les hauteurs des astres pour en conclure l'heure de et régler les pendules tant sur terre qu'en mer; observer des latitudes, des azimuths, pour orienter les cartes.

(c) Observer des éclipses de soleil, des éclipses des satellites de Jupiter, des occultations d'étoiles par la Lune pour en conclure les longitudes terrestres.

(II) Géodésiques

(a) Etablir des signaux de jour ou de nuit.

(b) Mesurer des bases et relever une suite de triangles du $1^{\text {er }}$ et du $2^{\mathrm{e}}$ ordre; connoître la meilleure condition de ces triangles.

(c) Lever les détails topographiques d'un terrain avec la planchette, la boussole, le cercle, \&a.

(d) Reconnoître sur le terrain la direction des lignes de plus grande pente, et celle des sections horisontales. Faire des nivellements avec un goniomêtre, avec un niveau d'eau, un niveau à bulle d'air, un baromètre, \&a.

(e) Différentes manières de disposer les minutes et les registres d'observations.

(f) Reconnoissances [militaires] topographiques.

(B) Calculs relatifs à ces opérations

(I) Astronomiques

(a) Usage des tables astronomiques dans les calculs des observations de latitude, de longitude, d'azimuth, \&a.

(b) Formules sur lesquelles sont fondés les calculs. 
(II) Géodésiques

(a) Calculs d'une suite de triangles, et des distances de leurs sommets à une méridienne et à sa perpendiculaire; des latitudes, longitudes et azimuths soit par le moyen de ces distances, soit en employant directement les longueurs des côtés des triangles.

(b) Calculs des différences de niveau, à l'aide des opérations trigonométriques ou des mesures barométriques, ou au moyen des observations faites avec le niveau d'eau, le niveau à bulle à d'air $\&$. .

(c) Déterminer l'étendue superficielle des empires, ou d'une portion quelconque d'un plan.

(C) Art du dessin

(I) Travail géographique relatif à ces opérations

(a) Sistème des échelles.

(b) Exercices sur les différentes manières de rapporter les plans d'après les minutes et les registres d'opérations, de tracer les différentes projections dont on a fait connoître la théorie, et de former les cartes d'après ces projections.

(c) Différentes manières de copier ou de réduire les cartes et les plans.

(d) Instruments propres cet usage.

(II) Mise au trait et lavis en teintes plates

(a) Tout ce qui est relatif à la mise-au-trait.

(b) La partie du lavis qu'on peut regarder comme une langue de convention au moyen de laquelle on peut exprimer les différentes cultures par des teintes plates circonscrites par des lignes.

(c) Tous les genres d'écritures et les signes conventionnels qu'on employe dans la carte.

(III) Dessin représentatif des objets

(a) Dans cette partie on n'employe pas simplement des teintes et des signes conventionnels, il faut le secours des couleurs, de la perspective aérienne et des projections d'ombres pour exprimer les édifices, les montagnes, les rochers, carrières, friches, bois, plantations et tous les accidents du terrain; les rivières, ruisseaux, lacs, étangs, chutes d'eau, mer $\&^{\mathrm{a}}$, le tout projetté sur le plan horisontal.

(b) Le genre de dessin à la plume, appliqué au même objet. 
(IV) Cartes militaires et profils de terrain

Le dessin de la carte qu'on appelle militaire, ou d'expédition, la perspective cavalière et le paysage, qui servent à représenter les sites sous divers aspects, ainsi que les établissements et mouvements militaires, ainsi que les divers corps de troupe, enfin tout ce qui peut être relatif aux différentes coupes ou profils de terrain.

(V) Gravure

Les procédés de la gravure des cartes et la pratique de cet art, nécessaire pour exécuter au besoin une gravure à l'eau forte.

(VI) Plan-relief

Les principes d'aprés lesquels se construisent ces plans et les procédes employés à leur exécution.

\section{(3) Connoisssances accessoires considérées dans leur généralite}

(I) Physico chimiques

Application des connoissances acquises à la formation des cahiers topographiques, à celle d'un dictionnaire topographique et militaire; à ce qui concerne la nature des terres, les qualités de leurs productions, les usines et produits de l'industrie et des arts; les causes du plus ou moins de salubrité.

(II) Economiques

Même application relativement à la population, aux recensemens, à la distinction des terraihs, à l'évaluation de leurs produits, à celle du travail, aux procédés de culture, au commerce, à ses débouchés, établissements et variations; aux animaux, forêts, routes et canaux.

(III) Historiques

Vues générales sur l'histoire ancienne et moderne de la France et de ses dépendances, ses divisions militaires et administratives, ses divers mœurs et usages $\&^{a}$. Pareilles vues sur les Etats voisins et sur leur topographie.

(IV) Militaires

Idées générales sur la composition des armées nationales et étrangères; sur les principaux faits de guerre, anciens et modernes considérés sous les rapports topographiques.

(V) Langues

Connoissance d'un des langues [anciennes ou] vivantes, spécialement les langues allemande, anglaise [ou italienne]. 


\subsection{Sommaire du Mémorial topographique et militaire, $1802-10^{123}$}

$\mathrm{n}^{\circ} 1$ Topographie, $3^{\mathrm{e}}$ trimestre an 10 (septembre 1802):

[Pascal-Vallongue]: Annonce (pp. 1-10).

Section I

\section{Chapitre I: Géographie}

Lacroix [et Barbié du Bocage]: Notice historique et analytique sur la construction des cartes géographiques (pp. 11-49).

\section{Chapître II: Géodésie}

C.R.M. Bonne: Des opérations géodésiques (pp. 50-144); Tables pour réduire les angles d'un plan à un autre plan (pp. 145-71). Capitaine d'artillerie $\mathrm{B}^{* * *}$ : De la détermination des hauteurs par des observations baromètriques (pp. 172-83).

$$
\begin{gathered}
\mathrm{n}^{\circ} 2 \text { Historique, } 4^{\mathrm{e}} \text { trimestre an } 10 \text { (novembre 1802): } \\
\text { [Pascal-Vallongue]: Avant-propos (pp. ii-xj). } \\
\text { Section II }
\end{gathered}
$$

Chapitre I: Reconnaissances militaires [reporté au $\left.n^{\circ} 4\right]$

\section{Chapitre II: Extraits analytiques militaires}

[Pascal-Vallongue]: Notice historique sur le Dépôt général de la Guerre en l'an 10 (pp. 1-41).

Lagardiolle: Notice sur les principaux historiens anciens et modernes considérés militairement (pp. 42-122).

Réflexions sur un ouvrage traduit de l'allemand sous le titre d'Esprit du système de guerre moderne (pp. 123-39). ${ }^{124}$

A. P. [Parigot]: De la bataille de Leuthen gagnée par le roi de Prusse, le 5 décembre 1757, contre l'armée impériale aux ordres du prince Charles de Lorraine (pp. 140-79).

Berthier: Rapport du ministre de la Guerre aux Consuls (...): Exposé des travaux du Dépôt général de la Guerre pendant le cours de l'an 10 (pp. 180-201).

\section{$\mathrm{n}^{\circ} 3$ Topographie, $1^{\text {er }}$ trimestre an 11 (janvier 1803): \\ [Pascal-Vallongue]: Avant-propos (pp. iij-xxiv). \\ Section I}

\section{Chapitre II: Géodésie}

Muriel: Des opérations géodésiques de détail (pp. 1-56).

\section{Chapitre III: Topographie}

[Soulavie]: Notice sur la topographie considérée chez les diverses nations de l'Europe, avant et après la carte de Cassini (p. 57147); Catalogue des meilleures cartes générales et particulières dont la connaissance peut être utile à un militaire (pp. 148-201).

$\mathrm{n}^{\circ} 4$ Historique, $2^{\mathrm{e}}$ trimestre an 11 (mars 1803);

[Pascal-Vallongue]; Avant-propos [Discours préliminaire pour

l'Essai sur les reconnaissances militaires] (pp. iij-lx).

\section{Chapittre I: Reconnaissances militaires}

\section{Section II}

A. Allent: Essai sur les reconnaissances militaires (pp. 1-208). Extrait d'une reconnaissance militaire de la Forêt Noire:

${ }^{123}$ De septembre 1802 à juin 1805, le Mémorial parut en édition in- $8^{\circ}$. L'ouvrage du colonel Henry, malgré un format différent (in- $\left.4^{\circ}\right)$, se présente comme une suite au Mémorial topographique et militaire. A ce titre, il fut réédité dans le Mémorial du Dépôt général de Guerre qui se poursuivit avec $n^{\circ} 8$ (cf. n.108). II était donc légitime de le considérer comme une septième livraison du premier journal.

${ }^{124}$ Ouvrage de Heinrich von Bülow (1760-1807). 


$$
<157>
$$

[Pascal -Vallongue]: Coup d'œil général [Considérations sur la Forêt noire] (pp. 209-12).

[Guilleminot]: Description militaire de la Forêt-Noire, partie méridionale (pp. 213-51).

$\mathrm{n}^{\circ} 5$ Topographie, $3^{\mathrm{e}}$ trimestre an 11 (septembre 1803];

P. V. [Pascal-Vallongue]: Avant-propos [Coup d'œil sur les systèmes de géologie, et sur le langage topographique] (pp. iij-li).

\section{Section I}

\section{Chapitre III: Topographie}

Procès-Verbal des conférences de la Commission chargée par les différents services publics intéressés à la perfection de la Topographie, de simplifier et de rendre uniformes les signes et les conventions en usage dans les cartes, les plans et les dessins topographiques (pp. 1-64).

\section{Chapitre IV: Gravure}

Bacler Dalbe: Notice sur la gravure topographique et géographique (pp. 65-91).

Suite du Chapitre III: Topographie

Des caractères et des hauteurs des écritures, pour les plans et cartes topographiques (pp. 92-125).

\section{Chapitre II: Géodésie (suite)}

L. Puissant; Analyse appliquée aux opérations géodésiques (pp. 126-92); Tables des réfractions moyennes et de leurs corrections pour les distances vraies au zénit (pp. 193-97).

$$
\begin{gathered}
\mathrm{n}^{\circ} 6 \text { Historique, } 4^{\mathrm{e}} \text { trimestre an } 11 \text { (juin 1805): } \\
\text { Pascal-Vallongue: Considérations sur le Tyrol (pp. iij-cij). } \\
\text { Section II }
\end{gathered}
$$

\section{Chapitre I: Reconnaissances militaires}

Extrait des Reconnaissances du Tyrol [recueillies par le Dépôt de la Guerre] (pp. 1-195).

Guilleminot: Second extrait d'une reconnaissance militaire de la Forêt Noire [partie septentrionale] (pp. 196-246).

$$
\mathrm{n}^{\circ} 7 \text { Topographie (1810): }
$$

Henry: Mémoire sur la projection des cartes géographiques, adoptée au Dépôt général de la Guerre (...), pour faire suite au Mémorial topographique et militaire (pp. 1-143); Tables (pp. 144-220). 